\title{
ANÁLISE DO CRESCIMENTO ECONÔMICO DOS MUNICÍPIOS DE MINAS GERAIS VIA MODELO MRW (1992) COM CAPITAL HUMANO, CONDIÇÕES DE SAÚDE E FATORES ESPACIAIS, 1991-2000
}

\author{
Vinícius de Azevedo Couto Firme * \\ José Simão FILHO ${ }^{\dagger}$
}

\begin{abstract}
Resumo
Este artigo analisou o crescimento da renda per capita municipal de Minas Gerais, entre 1991-2000, utilizando o modelo MRW (1992) com controle para condições de saúde e robusto contra efeitos espaciais. Os resultados indicaram que a renda converge entre 1,03\% e 1,70\% ao ano. Contudo, os modelos sem controles espaciais tendem a supervalorizar esse resultado. Somente o modelo com transbordamentos e regimes espaciais eliminou efetivamente a autocorrelação espacial, revelando a existência de clubes de convergência e um impacto de maior magnitude do capital físico em relação ao capital humano e à saúde. Ademais, verificouse um forte "efeito vizinhança" e uma relação positiva entre o estoque de capital físico e o impacto do capital humano sobre a renda.
\end{abstract}

Palavras-chave: Econometria Espacial; Economia Regional; Modelos de Crescimento.

\begin{abstract}
This article analyzed the growth of per capita income in the counties of Minas Gerais, between 1991-2000, using the MRW (1992) model with control for health conditions and robust against spatial effects. The results indicated that income converges between $1.03 \%$ and $1.70 \%$ per annual. However, the models without spatial controls tend to overvalue this result. Only the model with spillovers and spatial regimes was able to eliminate the spatial autocorrelation, revealing the existence of convergence clubs and a greater impact of physical capital when compared to human capital and health conditions. Moreover, there was a strong "neighborhood effect" and a positive relationship between the stock of physical capital and the impact of human capital on income.
\end{abstract}

Keywords: Spatial Econometrics; Regional Economics; Economic Growth Models.

JEL classification: R11, R12.

DOI: http : / /dx.doi.org/10.1590/1413-8050/ea640

\footnotetext{
${ }^{*}$ Universidade Federal de Juiz de Fora - Campus Governador Valadares (UFJF-GV). E-mail: vinicius.firme@ufjf.edu.br

† Programa de Pós-Graduação em Economia Aplicada da Universidade Federal de Juiz de Fora (PPGEA/UFJF).E-mail: simao.filho@ufjf.edu.br.
} 


\section{Introdução}

Entender os condicionantes do crescimento econômico de um país, ou mesmo uma região específica, é algo que intriga os economistas há algum tempo. ${ }^{1} \mathrm{Em}$ 1956, Robert Solow elaborou um modelo capaz de explicar parte da diferença verificada na renda per capita de países distintos. Posteriormente, Mankiw et al. (1992) desenvolveram uma "versão ampliada" desse modelo que considerava a importância do capital humano como insumo gerador de renda. ${ }^{2}$ Os efeitos do capital humano sobre o crescimento já vinham sendo estudados há algum tempo. Segundo Krueger (1968), esse fator poderia explicar mais de $50 \%$ do crescimento econômico. Além disso, os resultados de Barro (1991), fazendo uso dos dados de Summers \& Heston (1988), indicam que o capital humano, medido pelas taxas de matrícula nos ensino primário e secundário afetou positivamente o crescimento da renda per capita. ${ }^{3}$

O modelo Mankiw et al. (1992) revelou que moderadas mudanças nos recursos devotados à acumulação de capital físico e humano poderiam gerar grandes variações no produto per capita. Dessa forma, esse modelo aprimorou a capacidade de explicar as diferenças de renda entre regiões em relação ao modelo original de Solow (Romer 1996, p. 128). Mankiw et al. (1992) ainda sugerem que as condições de saúde seriam um importante componente do capital humano e, consequentemente, poderiam influenciar o crescimento econômico. ${ }^{4}$ Noronha et al. (2010), além de testar essa hipótese para os estados da economia brasileira, revelam que o fator "saúde", afetaria o crescimento de três formas: 1) diretamente, por meio da relação entre saúde e rendimentos individuais; ${ }^{5}$ 2) indiretamente, uma vez que indivíduos mais saudáveis tendem a ser estudantes mais produtivos; 3 ) Por meio do investimento em capital físico. ${ }^{6}$

Embora o modelo de Mankiw et al. (1992), considerando ou não o efeito "saúde", tenha avançado na discussão sobre o crescimento econômico, ele não considera o efeito espacial envolvido nesse processo. Visando suprir essa lacuna, Ertur \& Koch (2007) elaboram um Modelo de Solow Espacialmente Ampliado, no qual a importância do fator "espaço" é demonstrada formalmente. Em termos empíricos, negligenciar esse efeito poderia induzir a estimativas inconsistentes e/ou ineficientes (Anselin 1988, Anselin \& Bera 1998). Portanto, este trabalho buscou controlar os efeitos espaciais a fim de verificar se os modelos tradicionais (que desconsideram o espaço) incorriam em estimativas enviesadas.

\footnotetext{
${ }^{1}$ Em seu livro "Um inquérito sobre a natureza e as causas da riqueza das nações" (originalmente escrito em 1776), Adam Smith já demonstrava interesse sobre este tema (ver versão traduzida, Smith 2009).

${ }^{2} \mathrm{O}$ capital humano engloba diversas características individuais (conhecimento, experiência, perícia, atitude, aprendizagem) que tornam o recurso humano mais produtivo (Becker 1962, Hamermesh \& Rees 1993).

${ }^{3}$ A taxa de alfabetização também apresenta coeficiente positivo e significativo, mas apenas quando as duas "proxies" para capital humano anteriores não são consideradas.

${ }^{4}$ Embora argumentem sobre o fator saúde, estes autores acabam negligenciando esta variável em seus modelos.

${ }^{5}$ Segundo Noronha et al. (2010, p.271): "Poor health status causes considerable losses in individual income by decreasing labor productivity, the number of hours worked, and participation in the labor force.".

${ }^{6}$ Sachs (2001), argumentando sobre países com condições de saúde precária, revela: "Among other factors, business investments are very costly in these countries, partly because high rates of disease increase both the turnover of labor and rates of absenteeism and these factors raise training costs".
} 
Como será visto na seção 2, a literatura brasileira está repleta de trabalhos que buscaram analisar a variação da renda e o crescimento econômico. Entretanto, poucos deles estudaram esse efeito com um nível de desagregação municipal e nenhum deles buscou acomodar os dois principais efeitos espaciais (autocorrelação e heterogeneidade espacial), conjuntamente para a economia de Minas Gerais. Além disso, este trabalho avança na literatura ao testar diversas proxies para o capital físico e humano (inclusive, desagregando este último em: 1. educação, 2. educação ponderada por algum critério de qualidade e 3. condições de saúde). Para tanto, foi realizada uma extensa revisão das proxies mais utilizadas na literatura nacional, selecionando aquelas que se adéquam melhor aos modelos com base em critérios estatísticos. Feito isto, buscou-se comparar as abordagens tradicionais e espaciais dos modelos propostos por Solow (1956) e Mankiw et al. (1992), inclusive com a inserção do capital humano desagregado, para os municípios de Minas Gerais (MG) no período de 1991 a 2000.

Os resultados indicaram a presença de autocorrelação e heterogeneidade espacial envolvendo o crescimento dos municípios de Minas Gerais. De modo geral, verificou-se que os modelos sem controles espaciais supervalorizavam a velocidade de convergência dos municípios. Dentre os modelos utilizados, o único capaz de controlar, efetivamente, esses efeitos foi o modelo com transbordamentos e regimes espaciais. Assim, verificou-se a existência de clubes de convergência e um impacto positivo, e de maior magnitude, do capital físico frente ao capital humano e à saúde. Ademais, encontrou-se um forte efeito "vizinhança" e uma relação positiva entre o estoque de capital físico e o impacto do capital humano sobre o crescimento econômico.

O trabalho está subdividido da seguinte forma, além desta introdução. $\mathrm{Na}$ seção 2 é realizada uma breve revisão dos trabalhos que analisaram o crescimento econômico brasileiro de forma aplicada. A seção 3 apresenta os métodos formais de estimação dos modelos de Solow (1956), Mankiw et al. (1992) e o modelo de Solow Ampliado Espacialmente, proposto por Ertur \& Koch (2007). A seção 4 descreve a base de dados e a seleção das proxies utilizadas neste trabalho. Na seção 5 foi realizada a análise espacial da variável dependente - variação da renda per capita dos municípios " $Y$ " — por meio das técnicas de Análise Exploratória dos Dados Espaciais - AEDE. ${ }^{7}$ Logo após, na seção 6, foram estimados os modelos com a incorporação de ajustes espaciais. Em sequência, têm-se as considerações finais e referências.

\section{Trabalhos Empíricos utilizando modelos de Crescimento}

Na literatura brasileira, encontram-se diversos trabalhos que buscaram analisar a variação da renda e o crescimento econômico. Alguns autores estimaram modelos para os estados brasileiros e não consideraram questões espaciais como dependência espacial e heterogeneidade espacial, dentre estes, pode-se citar: Ferreira \& Ellery Jr (1996), Azzoni (1997), Pôrto Jr \& Ribeiro (2000), Azzoni et al. (2001), Dias \& Dias (2007), Trompieri Neto et al. (2008) e Cravo \& Soukiazis (2011). Alguns, inclusive, utilizaram uma especificação semelhante

\footnotetext{
${ }^{7}$ Segundo Anselin (1999, p.258): “A AEDE é a coleção de técnicas para descrever e visualizar distribuições espaciais, identificar localidades atípicas, descobrir padrões de associação espacial e sugerir diferentes regimes espaciais e outras formas de instabilidade espacial ou não estacionariedade espacial".
} 
à deste artigo: Nakabashi \& Salvato (2007) utilizam o modelo Mankiw et al. (1992) no intuito de testar uma nova proxy qualitativa para capital humano nos estados brasileiros. Já Cangussu et al. (2010) compararam a especificação de Mankiw et al. (1992) e a de Mincer, visando avaliar os desníveis de renda per capita nos estados brasileiros entre 1980-2000. Contudo, ambos os trabalhos ignoram possíveis efeitos espaciais. Os que utilizaram uma abordagem econométrica-espacial, para os estados brasileiros, foram: Magalhães et al. (2005), Silveira Neto \& Azzoni (2006), Barreto \& Almeida (2009) Montenegro et al. (2014).

Dentre os que analisaram os municípios e microrregiões brasileiras, se destacam: Pôrto Jr \& Ribeiro (2003), que realizaram uma análise da distribuição da renda per capita e do crescimento entre os municípios nordestinos. Oliveira et al. (2008) analisaram o crescimento econômico e a existência de convergência para os municípios do Rio Grande do Sul (RS). Fochezzato \& Stulp (2008) também fizeram um trabalho semelhante, porém utilizando um período diferente, para os municípios do RS. Menezes \& Azzoni (2006) utilizaram o salário para verificar se existe convergência entre as regiões metropolitanas brasileiras. Além disso, Ferreira \& Cruz (2010) e Coelho \& Figueiredo (2007) analisaram a convergência e desigualdade de renda considerando todos os municípios brasileiros. Este último verificou qual das hipóteses de convergência (absoluta, condicional ou de clubes) melhor descreve a dinâmica de crescimento para os municípios brasileiros entre 1970 a 2000. É importante ressaltar, que nenhum desses trabalhos utilizou variáveis de controle para os efeitos espaciais.

Monasterio \& Ávila. R. P. (2004) realizaram uma análise espacial sobre o crescimento econômico das áreas mínimas comparáveis (AMC) do RS. Barreto et al. (2010) analisaram os efeitos espaciais da variação da renda para os municípios do Ceará. Silva \& Resende (2009) utilizam um modelo espacial para comparar os determinantes do crescimento econômico dos municípios mineiros e alagoanos no período de 1991 a 2000. Embora os autores estejam abordando o mesmo período utilizado neste artigo, eles não se baseiam em nenhum modelo macroeconômico e tampouco controlam a heterogeneidade espacial. Perobelli et al. (2007) também implementam um modelo espacial para captar a existência de convergência do PIB para os municípios de MG. Contudo, desconsideram a importância do capital físico e humano e não controlam a heterogeneidade espacial.

Em se tratando de painel, Cravo et al. (2014) utilizaram uma abordagem espacial a fim de analisar o crescimento econômico de 508 microrregiões brasileiras entre 1980 e 2004. Já Resende et al. (2014) usam um painel espacial com diferentes escalas geográficas para analisar o crescimento brasileiro entre 1970 e 2000. Os autores estimaram modelos para os 27 Estados, 134 mesorregiões, 522 microrregiões e 3.657 áreas mínimas comparáveis (AMCs) e concluíram que a escala geográfica afetava os resultados. Este resultado é comum na área de econometria espacial e recebe o nome de "falácia ecológica". Segundo Anselin (2002, p.261) esse problema poderia causar viés nos resultados e ocorreria sempre que "parameters and other characteristics of a distribution are estimated at an aggregate level, but behavioral and socio-economic relations are inferred for another, disaggregate level". O autor ainda revela que "In economics, this issue is closely related to the aggregation problem". Portanto, seria de se esperar que os trabalhos dessa área utilizassem a menor desagregação espacial possível. Contudo, tal desagregação costuma trazer consigo a escassez de da- 
dos relevantes. Firme \& Freguglia (2013) fizeram um esforço nesse sentido, ao utilizar um painel espacial para analisar crescimento dos municípios brasileiros entre 1980 e 2010. Porém, os autores não incluíram todos os municípios brasileiros e recorrem a variáveis de qualidade duvidosa.

No caso do Brasil, a análise dos 5570 municípios seria a menor escala disponível. Todavia, devido à criação de novos municípios e à precária coleta de dados em regiões mais pobres, raramente consegue-se trabalhar com todos os municípios brasileiros. Portanto, a fim de evitar uma base de dados com missings, optou-se por considerar apenas os 853 municípios de Minas Gerais. Vale lembrar que esse Estado apresenta o maior número de municípios do país. Dessa forma, espera-se que a escala espacial utilizada intensifique o efeito espacial, pois, conforme a lei de Tobler (1970, p.236): "everything is related to everything else but nearby things are more related than distant things". ${ }^{8}$ Valendose dessa disponibilidade de dados municipais para MG, Maranduba Jr \& Almeida (2009) utilizaram dados em painel a fim de analisar os efeitos de políticas regionais e convergência sobre o PIB dos municípios da região.

Embora os trabalhos com dados em painel, mencionados nesta seção, tenham utilizado controles espaciais, eles ou ignoram a importância do capital físico e humano, e seus possíveis transbordamentos (Cravo et al. 2014, Resende et al. 2014) ou trabalham com variáveis questionáveis e missing data (Firme \& Freguglia 2013). Logo, este trabalho testou diversas proxies a fim de selecionar as variáveis mais relevantes ao crescimento econômico (com base no modelo macroeconômico descrito na seção 3) e controlou simultaneamente a autocorrelação e heterogeneidade espaciais utilizando dados municipais sem missings.

\section{O Modelo de Mankiw et al. (1992) e a importância do Espaço}

Segundo Solow (1956), o produto " $Y$ " pode ser determinado por meio de uma função de produção que considere o progresso tecnológico " $A$ ", o capital " $K$ ” e o trabalho " $L$ ". Assim, utilizando uma função Cobb-Douglas com retornos constantes de escala, tem-se que:

$$
Y_{y}=K(T)^{a}[A(t) L(t)]^{1-\alpha} \quad 0<\alpha<1
$$

onde: $\alpha$ e $(1-\alpha)$ são as elasticidades do produto em relação a $K$ e $L$, respectivamente. As unidades efetivas de trabalho, $A(t) L(t)$, cresce à taxa $(n+g)$. A razão capital-trabalho no estado estacionário tem relação positiva com a taxa de poupança e negativa com o crescimento populacional $(n) .{ }^{9}$ Logo, assumindo

\footnotetext{
${ }^{8}$ Neste ponto é relevante mencionar o trabalho de Montenegro et al. (2014). Os autores estimaram um modelo espacial para analisar o crescimento dos estados brasileiros e concluíram que as taxas de crescimento dos vizinhos não afetam significativamente as taxas de crescimento dos estados. Segundo eles, este resultado sugere que os Estados possuem mecanismos mais autônomos de crescimento (menos susceptíveis à influência espacial) quando comparados a unidades espaciais menores (microrregiões ou municípios).

${ }^{9}$ Nessa formulação (vide equação 1), o progresso tecnológico " $A$ ” é do tipo Harrod Neutral (aumentador de trabalho). Porém, identificar $A$ como mudança tecnológica, pode não ser apropriado segundo Tavares et al. (2001). Os autores destacam que este termo também reflete mudanças na forma organizacional de produção ou no esforço do trabalhador. Além disso, a literatura revela que outros fatores também poderiam afetar essa medida de produtividade, tais como: inflação (Jarret \& Selody 1982), grau de abertura econômica (Harrison 1996), educação (Miller \& Mukti 2000), desigualdade de renda (Khasnobis \& Bari 2000), desenvolvimento do sistema financeiro (Evans et al. 2002), investimentos públicos em infra-estrutura (Vallejos \& Valdivia 2000),
} 
que os fatores são remunerados de acordo com seu produto marginal, pode-se estimar os coeficientes associados à poupança $\left(s_{k}\right)$ e à depreciação efetiva do capital. Assim, a renda per capita no estado estacionário é determinada como:

$$
\ln \left[\frac{Y(t)}{L(t)}\right]=\ln A(0)+g t+\frac{\alpha}{1-\alpha} \ln \left(s_{k}\right)-\frac{\alpha}{1-\alpha} \ln (n+g+\delta)
$$

Parte da produção $(Y)$ é poupada à taxa constante e exógena $s$, e o restante consumido. O capital se deprecia a uma taxa constante $\delta$; a população cresce à taxa $n$; a tecnologia a uma taxa constante e exógena $g$. Caso $\alpha$ seja aproximadamente $\frac{1}{3}$, a elasticidade da renda per capita em relação à $s_{k}$ seria de, aproximadamente, 0,5 e a elasticidade em relação à $(n+g+\delta)$, de $0,5 .{ }^{10} \mathrm{MRW}$ estenderam o modelo de Solow incluindo o capital humano $(H)$ na análise. ${ }^{11}$

$$
Y(t)=K(t)^{\alpha} H(t)^{\beta}[A(t) L(t)]^{1-\alpha-\beta}
$$

Em que $\alpha$ e $\beta$ são as elasticidades do produto em relação aos insumos. Esse modelo, com a inclusão do capital humano, foi capaz de explicar quase $80 \%$ da variação da renda per capita dos países. Formalmente, tem-se:

$$
\begin{aligned}
\ln y_{t} & =\ln \left[\frac{Y_{t}}{L_{t}}\right] \\
& =\ln A_{0}+g t-\frac{\alpha+\beta}{1-\alpha-\beta} \ln (n+g+\delta)+\frac{\alpha}{1-\alpha-\beta} \ln s_{k}+\frac{\beta}{1-\alpha-\beta} \ln \left(s_{h}\right)
\end{aligned}
$$

onde $s_{h}$ representa a fração de renda investida em capital humano. Pela equação 4, pode-se observar que a renda, no estado estacionário, é diretamente correlacionada ao capital físico e humano e inversamente à taxa de crescimento populacional. Além disso, como a previsão de $\alpha$ continua sendo $\frac{1}{3}$, e estima-se que $\beta$ esteja entre $\frac{1}{3}$ e $\frac{1}{2}$, a inserção do capital humano tende a aumentar os efeitos do capital físico e do crescimento populacional. Por fim, a omissão do capital humano poderia gerar estimadores tendenciosos, uma vez que essa variável está correlacionada à taxa de poupança e ao crescimento populacional. No tocante à convergência, os autores relaxam a hipótese de os países estarem no estado estacionário. Logo, considerando o período de convergência obtém-se:

$$
\ln y_{t}=\left(1-e^{-\lambda t}\right) \ln y^{*}+e^{-\lambda t} \ln y_{0}
$$

Sendo $y^{*}$ a renda do estado estacionário (em unidades efetivas de trabalho) e $\lambda$ a taxa de convergência, onde: $\lambda=(n+g+\delta)(1-\alpha-\beta)$. Substituindo $y^{*} \mathrm{e}$ subtraindo $y_{0}$ de ambos os lados:

qualidade das instituições e políticas governamentais (infra-estrutura social) (Hall \& Jones 1999), dentre outros. Nesse caso, o próprio capital humano é um desses componentes geradores de produtividade.

${ }^{10}$ Note que, se a depreciação do capital " $\delta$ " e o avanço tecnológico " $g$ " são constantes entre as regiões analisadas, " $A$ " passa a representar a diferença de dotações, clima, instituições e etc. entre as regiões (Mankiw et al. 1992). Além disso, no estado estacionário, a razão capital-produto é uma constante e o estoque de capital se expande a taxa $n+g$. Os retornos marginais decrescentes dos fatores de produção implicam na hipótese de convergência no modelo de Solow. Assim, haverá convergência da renda per capita para o estado estacionário.

${ }^{11}$ Mankiw et al. (1992) concordam que as variáveis utilizadas por Solow afetam a renda per capita (sendo o capital e o trabalho responsáveis por mais da metade deste efeito). Além disso, reconhecem os efeitos da taxa de poupança e do crescimento populacional sobre a renda. Contudo, a magnitude desses termos parece ter sido subestimada no modelo original. 


$$
\ln \left(\frac{y_{t}}{y_{0}}\right)=\left(1-e^{-\lambda t}\right)\left[\begin{array}{l}
-\ln \left(y_{0}\right)+\frac{\alpha}{1-\alpha-\beta} \ln \left(s_{k}\right)-\frac{\alpha+\beta}{1-\alpha-\beta} \ln (n+g+\delta) \\
+\frac{\beta}{1-\alpha-\beta} \ln \left(s_{h}\right)+\ln A_{0}+g t
\end{array}\right]
$$

Os autores encontram uma taxa de convergência condicional próxima à de Solow ao incluir o capital humano. As previsões de Solow sobre as diferenças na taxa de retorno e no movimento do capital indicam que os países pobres apresentariam maiores retornos dos capitais físico e humano. Operacionalmente, o modelo pode ser apresentado como:

$$
\ln \left(\frac{y_{t}}{y_{0}}\right)=\beta_{0}+\beta_{1} \ln \left(y_{0}\right)+\beta_{2} \ln \left(s_{k}\right)+\beta_{3} \ln (n+g+\delta)+\beta_{4} \ln \left(s_{h}\right)+\varepsilon
$$

onde $y_{t}$ é renda per capita real; $y_{0}$ a renda per capita real inicial; $s_{k}$ a fração da renda investida em capital físico e; $s_{h}$ a fração da renda investida em capital humano.

Embora o modelo de Mankiw et al. (1992) tenha avançado na discussão sobre o crescimento, ele desconsidera a importância do espaço como fator relevante ao crescimento. Nesse sentido, Ertur \& Koch (2007) fazem uma contribuição importante ao modelo de Solow (1956) ao reconhecer a existência de interdependência tecnológica entre regiões distintas. Assim, partindo de uma função de produção semelhante à equação 1, assume-se que:

$$
A_{i}(t)=\Omega(t) k_{t}^{\phi}(t) \prod_{j \neq i}^{N} A_{j}^{y w_{i j}}(t)
$$

Desse modo, a tecnologia, $A_{i}(t)$, dependeria de três fatores: 1) um fator $\Omega(t)$, exógeno e idêntico entre as regiões, assim como proposto por Solow; 2 ) um termo $k_{t}^{\phi}(t)$, que indica que o nível de tecnologia aumenta com o crescimento do estoque de capital físico por trabalhador de cada região. Onde o parâmetro $\phi$, com $0 \leq \phi<1$, representa a magnitude da externalidade doméstica gerada pelo acúmulo de capital físico; 3) por fim, o terceiro termo, representado por $\prod_{j \neq i}^{N} A_{j}^{y w_{i j}}(t)$, diz respeito às externalidades espaciais da tecnologia. ${ }^{12}$

A função, na forma matricial, que descreve a renda por trabalhador da região $i$ no estado estacionário, pode ser obtida da função de produção $y=$ $A+\alpha k$. Portanto:

\footnotetext{
${ }^{12}$ Os autores pressupõem a existência de transbordamentos de conhecimento entre regiões vizinhas. A magnitude desse efeito dependeria grau de conectividade entre as regiões e tenderia a diminuir com a distância entre as mesmas. Lucas Jr (1988) já havia apontado que a proximidade gera um efeito spillover, pois permite que todos se beneficiem do conhecimento médio. A forma funcional utilizada por Ertur \& Koch (2007) para captar esse efeito na região $i$ é a média ponderada geometricamente do estoque de conhecimento dos vizinhos, denotado por $j$. O grau de interdependência entre as regiões, gerado pelo nível de externalidades espaciais, é descrito por $y$, onde $0<y<1$. Assume-se que esse parâmetro seja igual para todas as regiões, entretanto, os efeitos das externalidades espaciais sobre o nível de produtividade da região i dependem da conectividade entre essa região e os seus vizinhos. Ertur \& Koch (2007) sugerem que essa conectividade seja representada pelo termo exógeno $w_{i j}$, para $j=1, \ldots, N$ e $j \neq i$. Quanto maior a conectividade da região $i$ com os seus vizinhos, maiores os benefícios que $i$ obtém das externalidades espaciais. Logo, o estoque de tecnologia de uma região $i$ também dependerá da tecnologia de seus vizinhos, fazendo com que a renda de $i$ seja influenciada por seus vizinhos.
} 


$$
y=\Omega+(\alpha+\varphi) k-\alpha \gamma W k+\gamma W y
$$

Assim, quando $y=0$ e $\varphi=0$, obtém-se o modelo de Solow (1956). Reescrevendo essa equação para a economia $i$ e introduzindo a equação da razão capital-produto $\left(\frac{K^{*}}{Y^{*}}\right)$, no estado estacionário em logaritmo, tem-se:

$$
\begin{aligned}
\ln y_{i}^{*}(t)= & \frac{1}{1-\alpha-\phi} \ln \Omega(t)+\frac{\alpha+\phi}{1-\alpha-\phi} \ln s_{i}-\frac{\alpha+\phi}{1-\alpha-\phi} \ln (n+g+\delta)- \\
& \frac{\alpha y}{1-\alpha-\phi} \sum_{j \neq i}^{N} w_{i j} \ln s_{j}+\frac{\alpha y}{1-\alpha-\phi} \sum_{j \neq i}^{N} w_{i j} \ln \left(n_{j}+g+\delta\right)+ \\
& \frac{y(1-\alpha}{1-\alpha-\phi} \sum_{j \neq i}^{N} w_{i j} \ln y_{j}^{*}(t)
\end{aligned}
$$

Desse modo, a renda por trabalhador depende positivamente da taxa de poupança dos seus vizinhos e negativamente das taxas de crescimento da população dos vizinhos. Os retornos decrescentes do capital garantem que o crescimento no nível de capital físico por trabalhador de uma região tende a reduzir a taxa de crescimento da mesma, fazendo-a convergir para o seu nível de estado de estacionário. Contudo, um aumento no capital físico por trabalhador das regiões vizinhas, aumenta a produtividade da região i devido à interdependência tecnológica. ${ }^{13}$ Logo, os investimentos efetuados em uma região poderiam gerar impactos econômicos para além de sua própria fronteira. ${ }^{14}$ Por fim, somente pode-se afirmar que o crescimento da renda per capita é uma função negativa da renda inicial após controlar os demais fatores, como a taxa de poupança e o crescimento da população.

\section{Especificação das Variáveis e Fonte de Dados}

O modelo Mankiw et al. (1992) foi estimado para os municípios de Minas Gerais por meio de dados cross-section considerando o período de 1991 a 2000. Inicialmente, utilizaram-se as seguintes variáveis: crescimento da renda per capita $\ln \left(\frac{Y_{y}}{Y_{y-1}}\right)$, renda per capita inicial $\ln \left(Y_{t-1}\right)$, estoque de capital físico $\ln \left(K_{t}\right)$ e humano $\ln \left(H_{t}\right)$ e o somatório das taxas de crescimento populacional $(n)$, ganho tecnológico $(g)$ e depreciação $(\delta), \ln (n+g+\delta) .{ }^{15}$

Para $Y$, usou-se a renda per capita das famílias, disponível no Atlas do Desenvolvimento Humano no Brasil, versão 1.0.0, 2003. Quanto às taxas $(n+$

\footnotetext{
${ }^{13}$ Note que a externalidade do capital físico e a interdependência tecnológica apenas retardam o decrescimento da produtividade do capital físico. Logo, a convergência continua válida sob a hipótese: $\alpha+\left(\frac{\phi}{1-y}\right)<1$.

${ }^{14}$ Firme \& Vasconcelos (2014) mostram que esse efeito pode ser relevante até mesmo em escala estadual. No caso de Minas Gerais, mais de $20 \%$ dos investimentos acabam transbordando para os outros estados do Brasil.

${ }^{15}$ Os modelos deste trabalho foram estimados utilizando a especificação $\log$ - $\log$ que, segundo Wooldridge (2010, p.41-44), permite a existência de relações não lineares entre a variável dependente $(y)$ e as explicativas $(x)$. Além disso, os coeficientes obtidos dessa forma são as elasticidades de $y$ em relação à $x$. Cabe ressaltar também que, quando são utilizados dados espaciais, é recomendável que se trabalhe com variáveis intensivas (e não absolutas). Segundo Anselin (2005), isso evitaria que as variáveis fossem influenciadas pelo tamanho da população ou da área geográfica, diminuindo a probabilidade de se obter correlações espaciais espúrias. Logo, as variáveis: renda $(Y)$, capital fisco $(K)$ e humano $(H)$ foram contabilizadas em valores per capita.
} 
$g+\delta)$, considerou-se o valor proposto por Mankiw et al. (1992, p.413) para $g$ e $\delta$ : "We assume that $g+\delta$ is 0.05 ; reasonable changes in this assumption have little effect on the estimates". Já o crescimento populacional $(n)$ foi obtido no Atlas do Desenvolvimento Humano no Brasil, versão 1.0.0, 2003. ${ }^{16}$

No caso de $K$ e $H$, não existe consenso sobre quais seriam as melhores proxies para o modelo quando se utiliza uma desagregação municipal. Segundo Pereira et al. (2011, p.19): "Muitas variáveis consideradas em análises interestaduais e entre países não estão disponibilizadas de forma desagregada por município". Assim, vários autores têm utilizado variáveis alternativas que, em tese, poderiam captar o efeito do capital humano e físico.

Para o capital físico $(K)$, as mais utilizadas são:

1. Consumo de energia elétrica: Cangussu et al. (2010), Noronha et al. (2010), Barreto \& Almeida (2009) e Keppe \& Nakabashi (2009);

2. Estoque de capital residencial urbano: Soares (2009), apud Figueiredo (2011), Pereira et al. (2011) e Barros Neto \& Nakabashi (2011);

3. Despesa média de investimento do setor público e variação do capital residencial total: Salgueiro et al. (2011);

4. Gastos Públicos e Privados em Capital: Kroth \& Dias (2012);

5. Estoque de capital líquido do IPEADATA: Coelho \& Figueiredo (2007);

6. Fundo de Participação dos Municípios (FPM): Silva et al. (2008).

As principais críticas relacionadas a essas variáveis são:

1. O avanço tecnológico poderia diminuir o uso de energia elétrica mesmo sem contrapartida do estoque de capital físico (Barretto \& Mitrulis 2001).

2. O Estoque Líquido de Capital Privado (ELCP) seria preferível ao estoque de capital residencial (Santolin \& Figueiredo 2010). ${ }^{17}$

3. Para Salgueiro et al. (2011), o estoque de capital residencial incluiria apenas a parcela privada do capital físico. Logo, propuseram conjugá-lo com o investimento do setor público.

4. Seguindo essa linha, Kroth \& Dias (2012) usaram os Gastos Públicos e Privados em Capital. No entanto, tais dados não estão disponíveis para o período analisado neste trabalho.

5. O Estoque de capital líquido do IPEADATA é pouco utilizado e precisaria ser convertido em valores atuais (Santolin \& Figueiredo 2010). ${ }^{18}$

6. O FPM não foi significativo em Silva et al. (2008).

Com relação ao Capital Humano $(H)$, diverge-se sobre os componentes dessa variável. Alguns defendem o uso de aspectos quantitativos associados à educação:

\footnotetext{
${ }^{16}$ A fim possibilitar o uso do Logaritmo Natural sobre $(n+g+\delta)$, somou-se 1 ao resultado dessas variações.

${ }^{17}$ Os próprios autores ressaltam que o último cálculo para o ELCP, realizado pelo IBGE, ocorreu em 1985, o que inviabilizaria sua utilização. Contudo, essa variável apresentou uma correlação de 0,981 com o capital residencial em 1970 e de 0,978, em 1980. Logo, o capital residencial poderia ser uma boa proxy para o ELCP municipal.

${ }^{18} \mathrm{O}$ que seria complicado, pois não existem boas variáveis para efetuar tal conversão em nível municipal.
} 
1. Matrícula Escolar: Barro (1991).

2. Anos médios de Escolaridade: Solow (1956), Lucas Jr (1988), Mankiw et al. (1992), Cangussu et al. (2010), Coelho \& Figueiredo (2007) e Silva $\&$ Resende (2009). No entanto, argumenta-se que a qualidade da educação também deveria ser considerada.

3. Anos de escolaridade ponderados pelo IDEB, ENEM ou IDH: Soares (2009), apud Figueiredo (2011), Penna (2009), apud Figueiredo (2011), Nakabashi \& Figueiredo (2008) e Barreto \& Almeida (2009).

4. Combinação de anos de estudo, taxa de aprovação discente, percentual de professores com graduação completa e o número de alunos por turma: Nakabashi \& Salvato (2007). ${ }^{19}$ Há ainda autores que preferem utilizar algum tipo de especificação Minceriana. ${ }^{20}$

5. Capital Humano (IPEADATA): Pereira et al. (2011) e Santos et al. (2012). Por fim, há uma corrente que defende a inclusão das condições de saúde na composição do capital humano. Para estes, o efeito da saúde sobre o crescimento pode ser captado pelas seguintes variáveis.

6. Expectativa de vida: Knowles \& Owen (1995), Bloom et al. (2001) e Bhargava et al. (2001).

7. Taxas de mortalidade infantil e expectativa de vida aos cinco anos de idade: Barro (1996).

8. Mortalidade infantil e outras oriundas de complicações no pré-natal: Noronha et al. (2010).

Novamente, existem críticas com relação a essas variáveis. Segundo Islam (1995), Woessmann (2003) e Nakabashi \& Figueiredo (2008), as variáveis quantitativas não captam a qualidade do ensino e, muitas vezes, fazem o capital humano ser não significativo. Porém, Figueiredo (2011), após revisar trabalhos aplicados ao Brasil, revela que a mensuração da qualidade do ensino não alteraria significativamente os resultados. Ademais, o uso do IDH geraria endogeneidade. ${ }^{21}$ O mesmo ocorre com o Capital Humano minceriano. Quanto às condições de saúde, defende-se que sua inclusão poderia tornar a educação não significativa (Knowles \& Owen 1995) enquanto sua exclusão poderia supervalorizá-la (Hirvonen 2010). Além disso, Santos et al. (2012) encontraram evidências de causalidade no sentido da saúde para a renda no caso brasileiro. Porém, alguns trabalhos compilados em Mayer et al. (2000),

\footnotetext{
${ }^{19}$ Nakabashi \& Salvato (2007, p.220), argumentando sobre as diferenças entre seus modelos revelam que é possível utilizar as proxies de quantidade e qualidade de ensino conjuntamente (como um índice) ou separadas. "The difference among them is the human capital proxy. In the first one, it is used years of schooling $(h)$, in the econd, it is years of schooling times our index of education quality $\left(h^{\prime}\right)$, and in the third we look at the individual effects of the two proxies (qualitative and quantitative)".

${ }^{20} \mathrm{O}$ capital humano obtido da proposta de Mincer (1974) é, na realidade, uma medida de salário potencial, onde busca-se mensurar os retornos monetários, para o indivíduo, oriundos de investimentos em educação. Pressupõe-se que indivíduos qualificados são mais produtivos e auferem maiores salários (Kroth \& Dias 2012).

${ }^{21} \mathrm{O}$ IDH inclui explicitamente a renda. Portanto, o crescimento da renda aumentaria esta proxy de forma endógena. Nakabashi \& Figueiredo (2008, p.16) alertam para este problema, embora não o tenham tratado.
} 
incluíram a saúde e obtiveram resultados inconclusivos e/ou contrários ao esperado.

Sendo assim, testaram-se algumas proxies utilizadas na literatura a fim de verificar se há coerência com a teoria proposta por Solow (1956) e Mankiw et al. (1992). Feito isso, verificou-se qual seria a melhor combinação para compor o modelo MRW. Inicialmente, foram testadas as proxies para o capital físico $(K)$ com base no modelo tradicional de Solow. Os resultados da Tabela 1 revelaram que o consumo de energia elétrica industrial per capita de 2009 não foi significativo (ID 1 e 2). ${ }^{22}$ Porém, o consumo elétrico, com base no ano de 2011 (ID 3 e 4), foi significativo. ${ }^{23}$ No caso dessas proxies, optou-se por aquela que foi defasada pelo PIB industrial (ID 4), conforme os critérios de Akaike (AIC) e Schwarz (SC). ${ }^{24}$

Foram estimadas duas outras abordagens utilizando o consumo industrial de energia elétrica per capita. A primeira consistiu da divisão do consumo elétrico pelo número de indústrias de cada município (ID 7 a 10). A segunda ponderou esse consumo pela participação das indústrias em relação ao total de estabelecimentos de comércio e serviços (ID 11 a 14). No primeiro caso, nenhuma das variáveis foi significativa. Já no segundo, todas se mostraram significantes e optou-se por ID 14, devido aos critérios de AIC e SC. O estoque de capital residencial per capita (ID 5) também foi significativo e apresentou os menores valores AIC e SC dentre as variáveis testadas. Testaram-se outras possibilidades relacionadas a essa variável como: o crescimento médio anual do capital residencial (ID 17) ${ }^{25}$ e sua versão per capita (ID 18). Nesse caso, apenas ID 18 foi significativa. Além disso, verificou-se que a média anual de investimento público ${ }^{26}$ não foi significativa tanto em termos absolutos (ID 15) quanto per capita (ID 16). Esse resultado explica o fraco desempenho das proxies ID 19 e 20, que nada mais são que combinações lineares de ID 15 e 17 e ID 16 e 18 (versão per capita), respectivamente. ${ }^{27}$ Embora ID 20 tenha sido significativa, ela se mostrou inferior à ID 18, indicando que a combinação entre ID 16 e 18 piorou a especificação do modelo. Por fim, o fundo de participação municipal per capita (ID 6) não foi significativo.

\footnotetext{
${ }^{22} \mathrm{O}$ consumo industrial de energia elétrica municipal é disponibilizado pela CEMIG por meio dos anuários produzidos pelo SEBRAE/MG (2012). Infelizmente, o primeiro anuário refere-se ao ano de 2009. Dessa forma, buscou-se trazer o consumo elétrico de 2009 e 2011 para o ano de 2000 utilizando o crescimento do PIB municipal total ou industrial (disponíveis no IPEADATA, 2012) como taxa de desconto.

${ }^{23}$ Uma explicação refere-se ao número de municípios disponíveis em cada ano. Em 2009, a CEMIG disponibilizou o consumo elétrico de apenas 696 dos 853 municípios de MG. Já em 2011, esse número foi 839.

${ }^{24}$ Segundo Greene (2000), embora o critério SC penalize a inclusão de variáveis de forma mais intensa que o AIC, não há uma vantagem óbvia que permita definir qual destes é melhor.

${ }^{25}$ Valor do capital residencial de 2000 menos o valor de 1991 dividido pelo número de anos do período.

${ }^{26}$ Para essa proxy, utilizou-se a média anual da despesa de capital (investimento municipal) da Secretaria do Tesouro Nacional. Tal média foi calculada após os valores serem convertidos em valores de 1991 com base no IGP-DI/FGV. Tanto esse índice quanto a despesa de capital municipal foram obtidos no IPEA (2012).

${ }^{27} \mathrm{O}$ investimento público foi ponderado pela participação média (entre 1991 e 2000) do Estoque líquido de Capital fixo (máquinas e equipamentos) da administração pública nacional frente ao Estoque líquido de Capital fixo total brasileiro (equivalente a $8 \%$ ). No caso do crescimento do capital residencial, essa participação foi de $92 \%$ do total (considerou-se participação média, entre 1991 e 2000, do Estoque líquido de Capital fixo (máquinas e equipamentos) das empresas e famílias frente ao total nacional). Os estoques de capital fixo foram calculados por Morandi e Reis (2004), apud IPEA (2012).
} 
Esse primeiro estágio gerou quatro candidatas à proxy para $K$, sendo elas: ID $4,5,14$ e 18 . Assim, o próximo passo consistiu em verificar quais proxies, para o capital físico $(K)$ e humano $(H)$, que melhor especificariam o modelo MRW. Logo, diversas especificações foram testadas, considerando-se $K=I D(x)$ e $H=I D(y), \operatorname{com} x=[4,5,14$ e 18$]$ e $y=[21, \ldots, 35] .{ }^{28}$ Feito isso, definiu-se o melhor modelo com base nos critérios de AIC e SC. A inclusão de $H$ alterou o sinal das proxies para o capital físico, ID 4 e 14 (tornando-os contrários à teoria). Fato que resultou na exclusão das mesmas. No caso das proxies para $H$, apenas o IDH educação (ID 22), quando se considerou $\mathrm{K}=$ ID 5, não foi significativo. Desse modo, obteve-se quatro possíveis modelos. Dois desses modelos consideram o capital humano $(H)$, como uma variável única (ID 31) que inclui a quantidade e qualidade do ensino ${ }^{29}$ mais as condições de saúde (medido pelos anos de educação, ponderado pelo IFDM educação e saúde). São eles: a) $\mathrm{K}=$ ID5 e H = ID31; e b) $\mathrm{K}=\mathrm{ID} 18$ e H = ID31. Os outros dois desagregam o capital humano em quantidade de educação e Saúde [c) K=ID5, H1=ID21 e H2=ID24] e quantidade de educação ponderada pela qualidade do ensino (anos de educação, ponderado pelo IFDM educação) mais uma proxy para saúde (IFDM Saúde) [d) K=ID18, H1=(ID21 x ID22) e $\mathrm{H} 2=$ ID25].

Embora os modelos a, b, c e d, da Tabela 2, apresentem significância e sinal esperado para $K$ e $H$, o modelo " $c$ " obteve o maior $R^{2}$ ajustado e os menores valores para AIC e SC. ${ }^{30}$ Portanto, a proxy para capital físico $(K)$ será o estoque de capital residencial (ID5). Já o capital humano será desagregado em 2 componentes, onde o $1^{\circ}$ engloba a quantidade de educação $\left(H_{1}\right)$, enquanto o $2^{\circ}\left(H_{2}\right)$ capta condições de saúde (ver ID32 - Tabela 1).

Além das variáveis $Y,(n+g+\delta), K$ e $H$ que compõem o modelo Mankiw et al. (1992), utilizou-se uma matriz de pesos espaciais " $W$ " para capturar a autocorrelação espacial. Segundo Almeida et al. (2008), a matriz de pesos é a forma de expressar a estrutura espacial dos dados. Na literatura existem diversas opções de matrizes, que vão desde matrizes de contiguidade binária, passando pela determinação dos $k$ vizinhos mais próximos, entre outras, de conectividade mais complexa (maiores detalhes em Anselin 1988). Definir qual delas será utilizada é um passo importante para a elaboração da AEDE, pois todos os passos subsequentes dependerão dessa seleção (vide seção 5).

\footnotetext{
${ }^{28}$ As proxies utilizadas englobam, basicamente, 3 variáveis e suas combinações. São elas: 1) Média de anos de estudo das pessoas com 25 anos ou mais, calculadas pelo IBGE (ID 21); 2) IDH educação e saúde (ID 22 e 24, respectivamente); 3) IFDM educação e saúde (ID 23 e 25, respectivamente). Como foi discutido, o IDH vem sendo utilizado a fim de incluir aspectos qualitativos ao ensino. A novidade aqui seria a exclusão do IDH renda (devido à endogeneidade). Além disso, testou-se o Índice Firjan de Desenvolvimento Municipal (IFDM), que engloba um número maior de indicadores de educação e saúde quando comparado ao IDH (maiores detalhes em FIRJAN 2012). Todos os dados estão no sítio do IPEA (2012).

${ }^{29}$ De acordo com Nakabashi \& Figueiredo (2008), vários estudos não encontraram significância entre o capital humano e o crescimento por utilizarem "proxies" que não consideram os fatores quantitativos e qualitativos do capital humano. Segundo Khasnobis \& Bari (2000), a qualidade do ensino costuma depender do nível de desenvolvimento regional. Logo, considerar somente os anos de estudo não seria ideal, pois a contribuição do capital humano poderia ser superestimada (Nakabashi \& Figueiredo 2008).

${ }^{30}$ Note que o valor de AIC e SC para os modelos (a), (b), (c) e (d) são os mesmos na Tabela 1 e 2. Além disso, dado que se pretende observar os efeitos relativos das variáveis $K$ e $H$ sobre o crescimento econômico, optou-se por normalizá-las $\left[X_{\text {norm. }}^{i}=\frac{X^{i}-X^{\text {min. }}}{X^{\text {max. }}-X^{\min } .}\right]$. Esse procedimento evita que a escala interfira nos resultados e foi também utilizado nas demais estimações deste artigo.
} 
Tabela 1: Definição das melhores Proxies para Capital Humano (H) e Fí$\operatorname{sico}(\mathrm{K})$

\begin{tabular}{|c|c|c|c|c|c|}
\hline ID & (Sinal Esperado: + ) & Sinal & p-valor & AIC & SC \\
\hline 1 & $\begin{array}{l}\text { Consumo Elétrico Industrial. per } \\
\text { capita.1_Def.PIB }\end{array}$ & + & 0,950 & NR & NR \\
\hline 2 & $\begin{array}{l}\text { Consumo Elétrico Industrial. per } \\
\text { capita.1_Def.IND. }\end{array}$ & - & 0,999 & NR & NR \\
\hline 3 & $\begin{array}{l}\text { Consumo Elétrico Industrial. per } \\
\text { capita.2_Def.PIB }\end{array}$ & + & 0,005 & $-3162,62$ & $-3143,62$ \\
\hline 4 & $\begin{array}{l}\text { Consumo Elétrico Industrial. per } \\
\text { capita.2_Def.IND. }\end{array}$ & + & 0,005 & $-3162,63$ & $-3143,63$ \\
\hline 5 & Capital Residencial per capita. & + & 0,000 & $-3508,73$ & $-3489,74$ \\
\hline 6 & $\begin{array}{l}\text { Fundo de Participação dos Municí- } \\
\text { pios per capita. }\end{array}$ & + & 0,383 & NR & NR \\
\hline 7 & $\begin{array}{l}\text { Cons. Elét. Ind.1_Def.PIB /No. de } \\
\text { Indústrias Municipais }\end{array}$ & - & 0,570 & NR & NR \\
\hline 8 & $\begin{array}{l}\text { Cons. Elét. Ind.1_Def.IND/No. de } \\
\text { Indústrias Municipais }\end{array}$ & - & 0,550 & NR & NR \\
\hline 9 & $\begin{array}{l}\text { Cons. Elét. Ind.2_Def.PIB /No. de } \\
\text { Indústrias Municipais }\end{array}$ & + & 0,835 & NR & NR \\
\hline 10 & $\begin{array}{l}\text { Cons. Elét. Ind.2_Def.IND/No. de } \\
\text { Indústrias Municipais }\end{array}$ & + & 0,817 & NR & NR \\
\hline 11 & $\begin{array}{l}\text { Cons. Elét. Ind.1_Def.PIB x [No. } \\
\text { Ind./ (No. Com.+Serv.)] }\end{array}$ & + & 0,008 & $-3161,94$ & $-3142,94$ \\
\hline 12 & $\begin{array}{l}\text { Cons. Elét. Ind.1_Def.IND x [No. } \\
\text { Ind./ (No. Com.+Serv.)] }\end{array}$ & + & 0,009 & $-3161,63$ & $-3142,63$ \\
\hline 13 & $\begin{array}{l}\text { Cons. Elét. Ind.2_Def.PIB x [No. } \\
\text { Ind./ (No. Com.+Serv.)] }\end{array}$ & + & 0,000 & $-3169,16$ & $-3150,17$ \\
\hline 14 & $\begin{array}{l}\text { Cons. Elét. Ind.2_Def.IND x [No. } \\
\text { Ind./ (No. Com.+Serv.)] }\end{array}$ & + & 0,000 & $-3169,80$ & $-3150,81$ \\
\hline 15 & $\begin{array}{l}\text { Média Anual de Investimento Pú- } \\
\text { blico }\end{array}$ & - & 0,457 & NR & NR \\
\hline 16 & $\begin{array}{l}\text { Média Anual de Investimento Pú- } \\
\text { blico per capita. }\end{array}$ & - & 0,983 & NR & NR \\
\hline 17 & $\begin{array}{l}\text { Crescimento Médio do Capital Re- } \\
\text { sidencial }\end{array}$ & + & 0,730 & NR & NR \\
\hline 18 & $\begin{array}{l}\text { Crescimento Médio do Capital Re- } \\
\text { sidencial per capita. }\end{array}$ & + & 0,000 & $-3272,48$ & $-3253,48$ \\
\hline 19 & {$[($ ID $15 \times 0,08) \times($ ID $17 \times 0,92)]$} & - & 0,879 & NR & NR \\
\hline 20 & {$[($ ID $16 \times 0,08) \times($ ID $18 \times 0,92)]$} & + & 0,000 & $-3170,72$ & $-3151,72$ \\
\hline
\end{tabular}

Fonte: Elaboração própria do autor com base nos resultados do SpaceStat.

Notas: 1) O consumo industrial de energia elétrica municipal foi obtido no SEBRAE-MG (2012). As demais variáveis apresentadas estão disponíveis no IPEA (2012); 2) NR — Não reportado; 3 ) * Todas as proxies para $H$ obtiveram o sinal esperado (positivo) e apenas ID 22 , quando $K=I D 5$, não foi significativas a $5 \%$; 4$)^{* *} \mathrm{~K}=\mathrm{ID} 4$ Tornou-se negativa e significativa quando $\mathrm{H}=\mathrm{ID} 21 ; 5){ }^{* * *} \mathrm{~K}=\mathrm{ID} 14$ Tornou-se negativa e não significativa quando $\mathrm{H}=\mathrm{ID} 21$. 


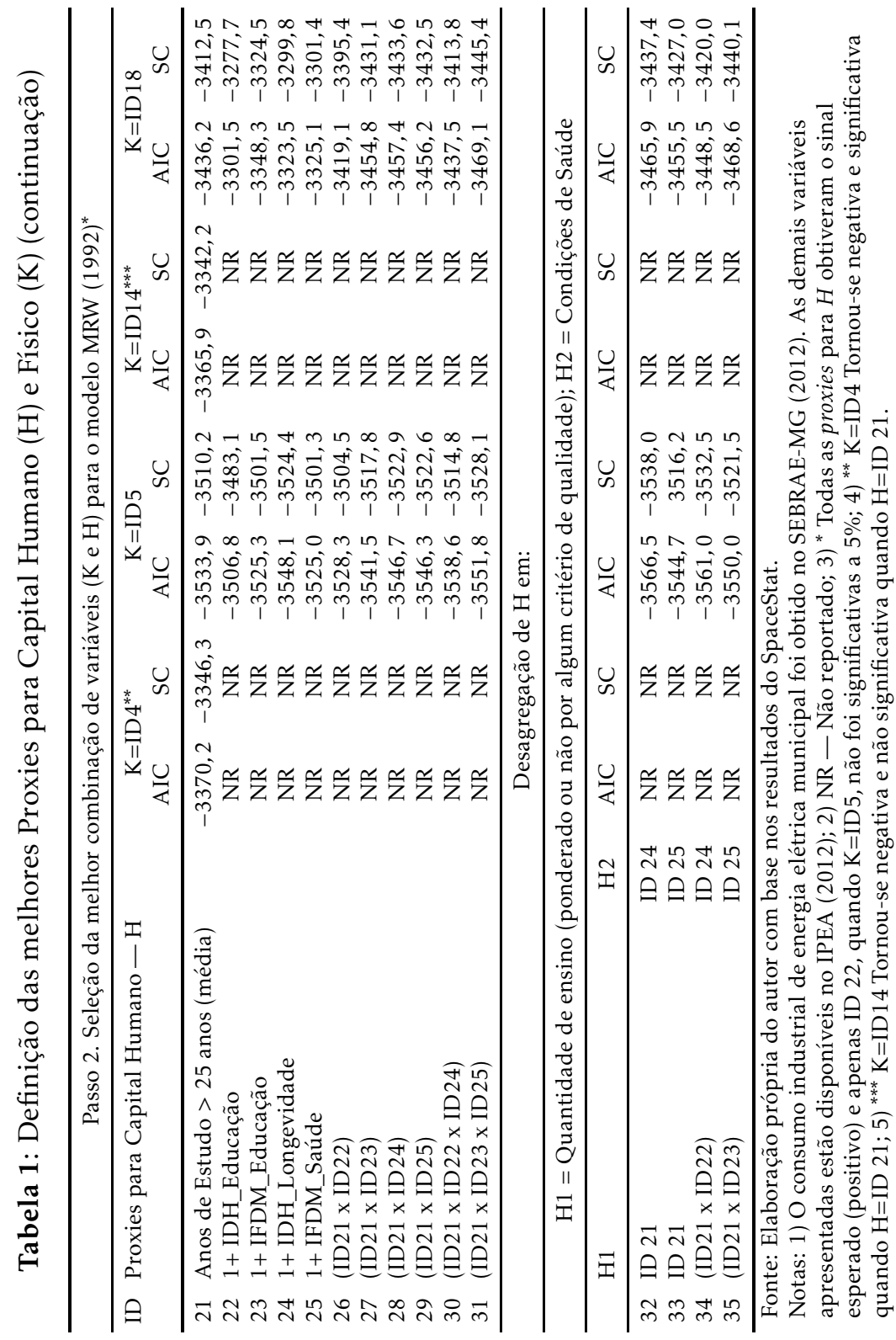




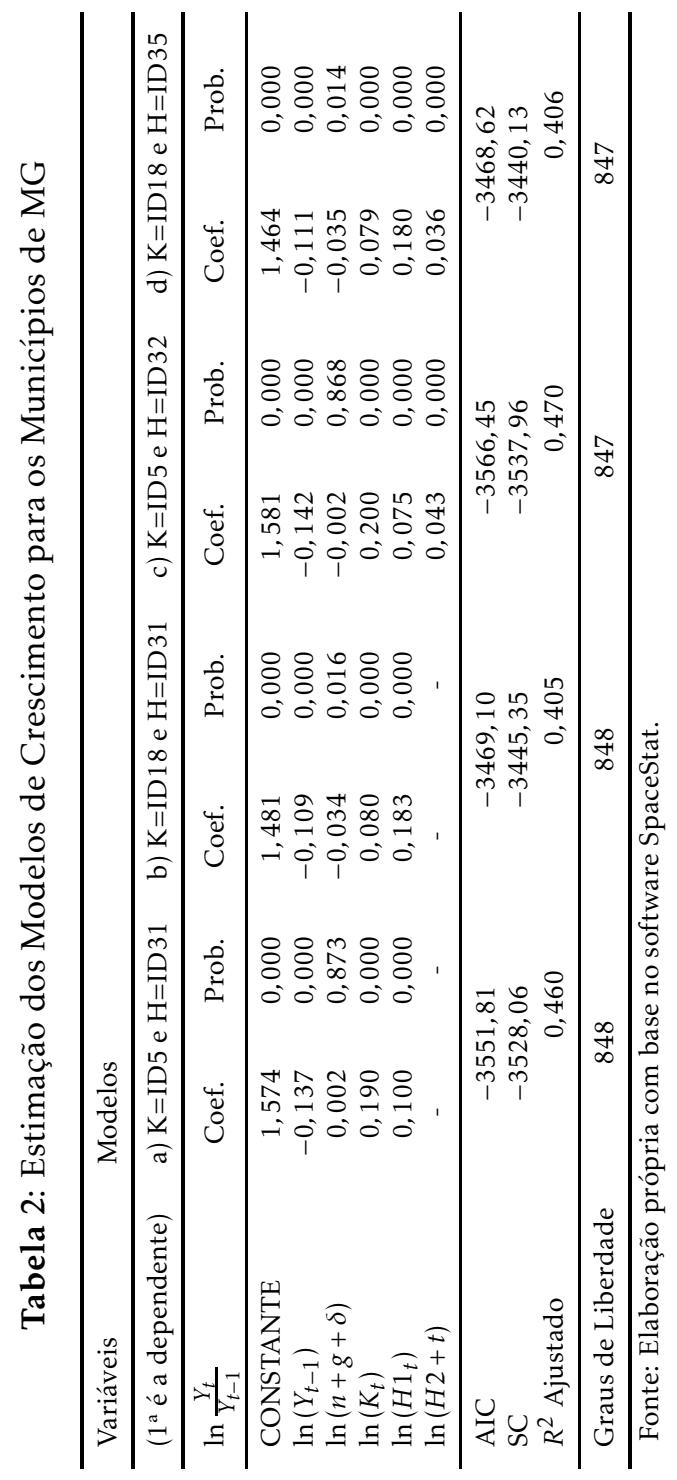




\section{Análise Espacial do Crescimento da Renda Per Capita de Minas Gerais}

Nesta seção, testou-se a existência de autocorrelação e heterogeneidade espacial na variação da renda per capita dos municípios mineiros, $\ln \frac{Y}{Y_{t-1}}$, entre 1991 e 2000. Inicialmente, calculou-se o $I$ de Moran a fim de verificar a existência de autocorrelação espacial. Segundo Cliff \& Ord (1981), a estatística I de Moran pode ser expressa como: ${ }^{31}$

$$
I_{i}=\left(\frac{n}{S_{0}}\right)\left(\frac{z_{t}^{\prime} W z_{t}}{z_{t}^{\prime} z_{t}}\right)
$$

onde $z_{t}$ é o vetor de $\mathrm{n}$ observações para o ano $t$ na forma de desvio em relação à média. ${ }^{32} W$ é uma matriz de pesos espaciais onde os elementos $w_{i i}$ na diagonal são iguais a zero, enquanto que os elementos $w_{i j}$ indicam a forma como a região $i$ é conectada à região $j$. $S_{0}$ é um escalar igual à soma de todos os elementos de $W .^{33}$

Diversas matrizes espaciais foram testadas com o objetivo de aumentar o rigor desse teste $e^{34}$ e identificar qual delas capta a maior autocorrelação sobre. ${ }^{35}$ Os resultados da Figura 1 indicam que há autocorrelação espacial positiva independente do tipo de matriz utilizada. Logo, parece que o crescimento da renda de um município depende, pelo menos em parte, das características de seus vizinhos. Além disso, a matriz de distância inversa ao quadrado $\left(\right.$ Dist $_{i n{ }_{2}}$ ) $)$ parece ser a mais indicada para ser utilizada neste trabalho.

I de Moran

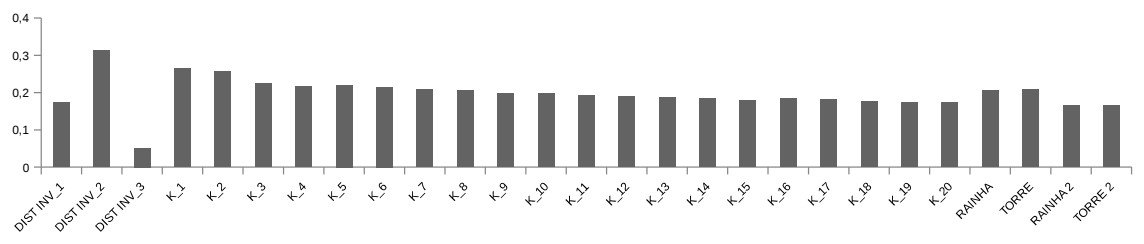

Elaboração própria com base no Software SpaceStat.

Figura 1: $I$ de Moran para $\ln \frac{Y}{Y_{t-1}}$, considerando Diversas Matrizes Espaciais

\footnotetext{
${ }^{31}$ Valores de $I$ maiores do que 1, indicam que há autocorrelação positiva. Nesse caso, prevalece o perfil Alto-Alto (AA) e Baixo-Baixo (BB). Ou seja, munićpios com elevado crescimento da renda tendem ter vizinhos que também obtiveram crescimento elevado (AA). O inverso vale para aqueles que crescem pouco $(\mathrm{BB})$. No caso de autocorrelação espacial negativa, prevalecem associações do tipo Alto-Baixo (AB) e Baixo-Alto (BA).

${ }^{32}$ No caso deste artigo, $z_{t}=\ln \frac{Y}{Y_{t-1}}$. Ou seja, representa a variação da Renda per capita dos municípios.

${ }^{33}$ Quando a matriz de pesos espaciais é normalizada na linha, isto é, quando os elementos de cada linha somam um, a expressão (11) fica expressa da seguinte forma: $I_{i}=\left(\frac{z_{t}^{\prime} W z_{t}}{z_{t}^{\prime} z_{t}}\right)$, com $t=1, \ldots, n$.

${ }^{34}$ Testaram-se matrizes de $K$ vizinhos mais próximos (onde $K=1, \ldots, 20$ ), matrizes de contiguidade convencionais Rainha e Torre e suas versões para os vizinhos de segunda ordem (Rainha2 e Torre2) e matrizes de distância inversa, distância inversa ao quadrado e distância inversa ao cubo. Respectivamente, Dist $_{i n v_{-} 1}$, Dist $t_{i n v_{-} 2}$ e Dist $t_{i n v_{-} 3}$.

${ }^{35}$ Tal procedimento para seleção da matriz de pesos espaciais está baseado em Baumont (2004, p.13) e vem sendo utilizado por diversos autores (Oliveira et al. 2011, Carvalho \& Almeida 2010, Maranduba Jr \& Almeida 2009).
} 
Apesar de o I de Moran global indicar uma autocorrelação espacial positiva, nada garante que as variáveis utilizadas para explicar a variação da renda irão gerar resultados semelhantes para todos os municípios de Minas Gerais. Características como cultura e localização podem influenciar o impacto dessas variáveis. Tal efeito é conhecido como heterogeneidade espacial. ${ }^{36}$ A fim de observar quais regiões contribuíram para a existência de autocorrelação espacial, implementou-se uma medida de autocorrelação espacial local (LISA). ${ }^{37}$ Segundo Le Gallo \& Ertur (2003), a estatística LISA, baseada no I de Moran local, é: ${ }^{38}$

$$
I_{i, t}=\frac{X_{i, t}-\mu_{t}}{m_{0}} \sum_{j} w_{i, j}\left(x_{i, j}-\mu_{t}\right) \operatorname{com} m_{0}=\frac{\left(x_{i, t}-\mu_{t}\right)^{2}}{n}
$$

onde $x_{i, t}$ é a variável de interesse na região $i$ para o ano $t, \mu_{t}$ é a média das observações das regiões no ano $t$ para a qual o somatório em relação a $j$ é tal que somente os valores vizinhos de $j$ são incluídos. Essa estatística tem interpretação semelhante à do $I$ de Moran global.

De acordo com Anselin (1995), a estatística LISA avalia a hipótese nula de ausência de associação espacial local. ${ }^{39}$ Como os Mapas de Clusters, calculados na Figura 2, revelam a existência de grupos de municípios com características próprias, rejeita-se a hipótese de que o território de Minas Gerais seja espacialmente homogêneo.
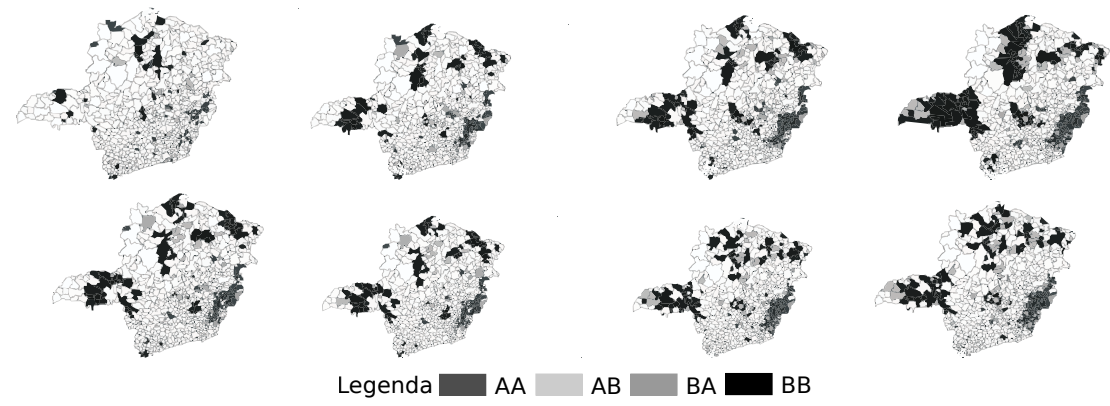

Elaboração dos autores com base no Software GEODA.

Nota: NS = não significante a $5 \%$.

Figura 2: Clusters do Crescimento de renda per capita dos municípios de MG (1991-2000)

\footnotetext{
${ }^{36} \mathrm{O}$ conceito de heterogeneidade espacial está relacionado com a ideia de instabilidade do comportamento econômico no espaço. Logo, pode haver características intrínsecas a cada região ou agrupamento espacial que afetam os processos econômicos (Le Gallo \& Ertur 2003, Anselin 1988, Anselin \& Bera 1998).

${ }^{37}$ Para Anselin (1995), um "Local Indicator of Spatial Association (LISA)" deve possuir, para cada observação, uma indicação de clusters espaciais significativos de valores similares em torno da observação (ex. região). Ademais, o somatório dos LISAs deve ser proporcional ao indicador de autocorrelação espacial global.

${ }^{38}$ Outras estatísticas do tipo LISA, menos usadas, são o "c de Geary" local e o "Gama Local" (Anselin 1995).

${ }^{39}$ A distribuição marginal da estatística LISA é de difícil apuração e requer que se trabalhe com resultados assintóticos. Logo, a alternativa é a utilização de uma aleatorização condicional ou uma permutação que permita auferir pseudoníveis de significância. Os níveis de significância das distribuições marginais podem ser aproximados por intermédio das desigualdades de Bonferroni ou por meio da estrutura proposta por Sidák (1967) apud Anselin (1995). Neste trabalho, utilizouse a análise de Bonferroni.
} 
De acordo com a Figura 2, existem alguns clusters de municípios AA, próximos à divisa de Minas Gerais (MG) com o Espírito Santo, que talvez mereçam um estudo de fronteira a fim de verificar se existem clusters AA interestaduais. Tais clusters poderiam explicar melhor o crescimento dos municípios de MG. Ademais, existem grupos do tipo BB concentrados na região norte e nordeste do estado, próximo à divisa com a Bahia. Outro cluster do tipo BB pode ser visto no Oeste do estado, na região do Triângulo Mineiro e Alto Parnaíba, incluindo as microrregiões de Frutal, Uberaba e Uberlândia.

Logo, esta seção revelou que há autocorrelação espacial associada ao crescimento da renda per capita em MG, tanto por meio da análise global quanto local. Ademais, a análise local indicou que há heterogeneidade espacial em MG. Tais resultados reforçam o modelo proposto por Ertur \& Koch (2007) e revelam que o espaço pode afetar o crescimento econômico. Vale lembrar que ambos os efeitos espaciais, se não tratados, induzem a estimativas inconsistentes e/ou ineficientes (Anselin 1988, Anselin \& Bera 1998).

\section{Modelos e Análise de Resultados}

Os modelos estimados consideraram as variáveis propostas por Mankiw et al. (1992) e a possibilidade de transbordamentos espaciais associados às variáveis explicativas e à própria variável dependente, conforme especificado por Ertur $\&$ Koch (2007) (ver equação 10). Além disso, o capital humano foi subdivido em ensino e condições de saúde (vide seção 4). Assim:

$$
\begin{aligned}
\ln \left(\frac{y_{t}}{y_{t-1}}\right)= & \beta_{0}+\beta_{1} \ln y_{y-1}+\beta_{2} \ln n+g+\delta+\beta_{3} \ln k_{t}+\beta_{4} \ln h_{t}^{a}+\beta_{5} \ln h_{t}^{b}+ \\
& \beta_{6} W \ln y_{t-1}+\beta_{7} w \ln n+g+\delta+\beta_{8} W \ln k_{t}+\beta_{9} W \ln h_{t}^{a}+ \\
& \beta_{10} W \ln h_{t}^{b}+\rho W \ln \left(\frac{y_{t}}{y_{t-1}}\right)+\varepsilon
\end{aligned}
$$

sendo, $\varepsilon \sim(0, \Omega)$. Onde $\beta_{0}$ é a constante e $\beta_{i}$ são coeficientes que acompanham as variáveis explicativas. Sendo que $i=1, \ldots, 5$, referem-se ao modelo MRW e $i=6, \ldots, 10$ representam essas variáveis defasadas espacialmente. $\rho$ é o coeficiente associado à variável dependente defasada espacialmente. Logo, $\rho \neq 0$ sugere a existência de autocorrelação espacial. $W$ é um termo de erro normalmente distribuído e representa a matriz de pesos espaciais (ver Figura 1). Em resumo, tem-se os seguintes modelos oriundos da equação 13:

Modelos sem componente espacial:

1) Solow (1956): $\rho=\lambda=\beta_{i}=0$; $\operatorname{com} i=4, \ldots, 10$;

2) Mankiw et al. (1992) com 1 proxy para $H: \rho=\lambda=\beta_{i}=0$; $\operatorname{com} i=$ $5, \ldots, 10$

3) Mankiw et al. (1992) com 2 proxies para $H: \rho=\lambda=\beta_{i}=0$; com $i=$ $6, \ldots, 10$.

Modelos espaciais (partindo do modelo sem componente espacial $\mathrm{n}^{\circ} 3$ ):

1) Regressivo Cruzado (Modelo de transbordamento): $\beta_{i} \neq 0$; com $i=6, \ldots$, $10 ; 40$

\footnotetext{
${ }^{40}$ Rey \& Montori (1999) argumentam que esse modelo pode ser estimado por MQO. Além disso, a ausência de um termo defasado espacialmente gera um impacto local e pode provocar viés nos coeficientes estimados.
} 
2) Defasagem: $\rho \neq 0 ;^{41}$

3) Durbin (Transbordamento com defasagem): $\rho \neq 0$ e $\beta_{i} \neq 0$; com $i=$ $6, \ldots, 10$

Inicialmente, estimou-se o modelo de Solow (1956) e Mankiw et al. (1992) regressivo cruzado por meio dos Mínimos Quadrados Ordinários (MQO). Os resultados da Tabela 3 indicam que o modelo (2), MRW com inserção das condições de saúde, foi superior ao (1), Solow, em todos os testes de qualidade (AIC, SC e R2 ajustado). No entanto, como o I de Moran calculado sobre os resíduos desses modelos indica a existência de autocorrelação espacial, estimouse um modelo de transbordamento, com a inclusão das variáveis explicativas defasadas espacialmente (3). Embora esse modelo tenha se mostrado superior aos dois anteriores (segundo os mesmos critérios de qualidade) ele controlou apenas parte da autocorrelação espacial [ $I$ de Moran reduz de 0,41 (Solow) e 0,39 (MRW), para 0,28].

O modelo de transbordamento com defasagem espacial (4) traz consigo o problema da endogeneidade ${ }^{42}$ e precisou ser estimado pelo método dos Mínimos Quadrados em Dois Estágios (MQ2E), utilizando os instrumentos recomendados por Kelejian e Prucha (1998). Além disso, usou-se a matriz de variância-covariância consistente de White para acomodar a heterocedasticidade. $^{43}$ Os resultados mostram que a especificação (4) produziu erros com maior nível de autocorrelação espacial quando comparada ao modelo de transbordamento (3). ${ }^{44}$ A dificuldade em se eliminar esse efeito espacial pode estar associada à não normalidade dos resíduos (detectada via teste de Jarque-Bera). Segundo Oliveira et al. (2011) e Maranduba Jr \& Almeida (p.595 2009), a ausência de normalidade dos erros pode ser corrigida por meio do mapeamento dos resíduos da regressão. Assim, é possível detectar os erros discrepantes (outliers) e utilizar dummies para captar esse efeito. ${ }^{45}$ Logo, buscou-se verificar se a correção desse problema poderia eliminar a autocorrelação espacial associada ao melhor modelo estimado até o momento, ou seja, o modelo de transbordamento (3) (Tabela 3).

\footnotetext{
${ }^{41}$ Nesse caso, a variável dependente espacialmente defasada é introduzida como variável exógena no modelo e pode ser entendida como a média de crescimento das regiões vizinhas. Esse tipo de dependência tem alcance global (Anselin \& Bera 1998, p.246) e pode gerar estimativas inconsistentes.

${ }^{42} \mathrm{O}$ termo tende a ser correlacionada com o termo de erro (endógeno). O fato é que variações na renda de um município influenciam a renda de seus vizinhos, que por sua vez afetam a renda deste município. Visando contornar esta questão, utilizou-se o método de Mínimos Quadrados em Dois Estágios (MQ2E) considerando, como instrumento, as variáveis explicativas e suas respectivas defasagens espaciais, que, a princípio, possuem alta correlação com a variável dependente e não possuem correlação com o termo de erro (Kelejian \& Prucha 1998) (Oliveira et al. 2011, p.270) também se valem destes instrumentos.

${ }^{43}$ A matriz de White também é utilizada por Maranduba Jr \& Almeida (2009) e Oliveira et al. (2011).

${ }^{44}$ Note que a inclusão de $W \ln \frac{y_{t}}{y_{t-1}}$ impossibilita a comparação direta entre os coeficientes obtidos nas demais estimações onde esse termo não foi incluído. Imagine o seguinte exemplo: (a) $y=\beta_{0}+\beta_{1} x+\varepsilon$. Nesse caso, $\beta_{1}$ representa o efeito marginal de $x$ sobre $y$. Agora inclua o termo $W y$ na função. Assim: (b) $y=\beta_{0}+\rho W y+\beta_{1} x+\varepsilon$. Após calcular a forma reduzida dessa função é possível verificar que o impacto de $x$ sobre $y$ será: $\left[(I-\rho W)^{-1} \beta_{1}\right]$. Logo, para que os coeficientes dos dois modelos fossem comparáveis, seria necessário calcular o efeito direto e indireto de $x$ para o modelo (b). Desse modo, deve-se evitar a comparação direta entre os coeficientes da regressão 4 e as demais especificações da Tabela 3 (mais detalhes em Lesage \& Pace 2009).

${ }^{45}$ Utilizou-se o método Box Plot, com hinge $=1,5$, por meio do software GEODA, para detectar os outliers.
} 
A inclusão das dummies $\left(D \_m x\right.$ e $\left.D \_m n\right),{ }^{46}$ de fato, corrigiu a não normalidade dos erros (modelo 3.1). Além disso, houve uma melhora nos testes de qualidade da regressão e uma nova parcela da autocorrelação foi controlada ( $I$ de Moran diminui de 0,28 para 0,20). Como o teste de Breusch-Pagan ainda rejeita a hipótese de homocedasticidade, utilizaram-se a matriz de variância e a covariância robusta de White para acomodar esse efeito. Assim, os resultados indicam que a única variável não significativa no modelo foi $\ln (n+g+\delta)$.

Existem duas diferenças importantes entre o modelo original de Mankiw et al. (1992) e sua versão estimada neste artigo que poderiam explicar os resultados obtidos para $\ln (n+g+\delta)$. A primeira refere-se à escala geográfica $(\mathrm{mu}-$ nicípios versus países) e a segunda ao período analisado (1991 a 2000 versus 1960 a 1985). Na versão de MRW (1992), os custos de transporte da época somados à dificuldade burocrática, financeira e social de mudar para outro país, praticamente inviabilizavam a migração. ${ }^{47}$ Portanto, a variável $n$ indicava basicamente a diferença entre os indivíduos que nasciam e morriam. Sendo assim, um crescimento acelerado de $n$ reduzia a renda per capita, uma vez que mais pessoas precisariam dividir o montante produzido (PIB). No atual artigo, a decisão de migrar é muito menos onerosa e o próprio crescimento da renda, de uma determinada região, poderia atrair habitantes de localidades vizinhas, o que tornaria o efeito de $n$ não só ambíguo como endógeno. Tal hipótese também parece ser corroborada por Barro \& Sala-I-Martin (1999, cap.11). Segundo esses autores, a proximidade facilitaria a mobilidade dos fatores de produção e, portanto, o efeito da migração não deveria se negligenciado.

Quanto às demais variáveis do modelo 3.1, pode-se destacar que, assim como foi verificado em diversos trabalhos, inclusive em Mankiw et al. (1992), a constante obteve o maior coeficiente $(\beta)$. O capital físico $\left[\ln \left(K_{t}\right)\right]$, humano $\left[\ln \left(H 1_{t}\right)\right]$ e as condições de saúde $\left[\ln \left(H 2_{t}\right)\right]$ são positivamente correlacionados com o crescimento dos municípios e a magnitude de seus $\beta$ coeficientes (lembrando que tais variáveis foram normalizadas, o que possibilita esse tipo de argumentação) sugere que o impacto dessas variáveis sobre o crescimento apresenta o seguinte ordenamento: $\beta_{k}>\beta_{H 1}>\beta_{H 2}$ (Tabela 3).

Quando o efeito transbordamento dessas variáveis é considerado, percebese que apenas as condições de saúde $\left[W_{-} \ln \left(H 2_{t}\right)\right]$ geram efeitos positivos sobre os crescimento. Logo, parece que a melhora no nível de saúde dos vizinhos de um município $i$, favorece o crescimento desse município. Esse efeito pode ser oriundo da facilidade de migração entre os municípios. Logo, o município $i$ poderia utilizar a mão de obra mais saudável da vizinhança para realizar trabalhos com maior eficiência, aumentando a produtividade nesse município.

Note que tanto o capital físico $(K)$ quanto o humano (mensurado pela quantidade e qualidade do ensino - $H 1$ ) teriam maior dificuldade de migrar quando comparados ao trabalhador saudável (H2). Logo, se os vizinhos de $i$ aumentarem seus estoques de capital físico ou investirem em educação, é

\footnotetext{
${ }^{46}$ No Apêndice, Tabela A.1, é possível verificar quais foram os outliers superiores e inferiores para cada modelo.

${ }^{47} \mathrm{Na}$ abordagem da teoria do capital humano, a migração é uma escolha racional tomada a partir da comparaçao entre o fluxo de benefícios esperado e os custos financeiros e/ou psicológicos associados à mobilidade regional (Sjaastad 1962). Esse custo-benefício é afetado por fatores, como: condições econômicas regionais (ex. diferenciais de salários, oportunidades de emprego, custo de vida) e custos da migração (sendo estes positivamente correlacionados à distância do local de origem e destino). Características individuais (ex. idade, sexo, estado civil, etc.) também podem afetar a decisão de migrar (Massey 1990, Borjas 1987, 2001).
} 
possível que a melhora relativa da infraestrutura faça com que parte dos trabalhadores saudáveis deixe o município $i$ em direção aos seus vizinhos. Isso explicaria o sinal negativo de $W_{-} \ln \left(K_{t}\right)$ e $W_{-} \ln \left(H 1_{t}\right)$. O sinal positivo de $W_{-} \ln (n+g+\delta)$ parece corroborar essa tese. Como se trata de uma variável com possibilidade de migração, o crescimento populacional dos municípios vizinhos de $i$ poderia favorecer o crescimento econômico de $i$ ao fornecer os trabalhadores necessários a esse crescimento.

Além disso, o sinal negativo associado à $\ln \left(Y_{t-1}\right)$, encontrado em todos os modelos, indica uma tendência de convergência da renda per capita dos municípios de MG. Na realidade, $\ln \left(Y_{t-1}\right)$ representa apenas o impacto direto da renda inicial. Logo, para obter a convergência correta, deve-se considerar também o efeito indireto, $W_{-} \ln \left(Y_{t-1}\right)$. Dessa forma, é possível calcular a velocidade de convergência, de acordo com a derivação do modelo de Barro e Sala-i-Martin (1992) apud Rey \& Montori (1999) e verificar se os resultados obtidos estão em conformidade com a literatura. Outra forma de analisar a velocidade de convergência $(\theta)$ refere-se ao conceito de meia-vida, que mede o tempo necessário, avaliado em anos, para que as desigualdades regionais associadas à renda sejam reduzidas pela metade. ${ }^{48}$

A velocidade de convergência, obtida nos modelos da Tabela 3, oscilou entre $1,03 \%$ e $1,70 \%$, valores próximos aos observados na literatura. ${ }^{49}$ Vale destacar que, mais uma vez, o melhor modelo estimado (3.1) captura apenas uma parte da autocorrelação espacial. A dificuldade em se controlar esse efeito não é uma peculiaridade única deste artigo. Grande parte dos trabalhos nem mesmo verifica se a autocorrelação espacial nos resíduos foi removida após a estimação. O fato é que, mesmo utilizando modelos espaciais, alguns autores conseguem apenas atenuar esse efeito, sem controlá-lo em sua totalidade [como foi o caso de Oliveira et al. (2011)]. No entanto, ainda existe uma questão, não trabalhada até agora, que poderia solucionar esse problema. Refere-se à heterogeneidade espacial. Conforme mencionado anteriormente, esse efeito propicia a formação de clusters espaciais, que contribuem para a existência de autocorrelação espacial. ${ }^{50}$

\footnotetext{
${ }^{48}$ Segundo os autores, a taxa de convergência $(\theta)$ é dada pela equação: $\theta=\left[\frac{\ln (I M T-1)}{-t}\right]$, em que $I M T$ é o Impacto Marginal Total da renda inicial, $\left\{\beta\left[\ln \left(Y_{t-1}\right)\right]+\beta\left[W_{-} \ln \left(Y_{t-1}\right)\right]\right\} ; t$ é o número de anos no período. Portanto, $\theta$ mede a taxa de convergência anual. Já o cálculo do tempo de meiavida é: $M V=\left(\frac{\ln 2}{\theta}\right)$.

${ }^{49}$ Diversos autores têm encontrado velocidades de convergência em torno de $2 \%$ a.a. (Barro \& Lee 1994, Sala-I-Martin 1995, Durlauf \& Johnson 1995, Rivera-Batiz 1993, Shioji 1993). Na literatura nacional não tem sido diferente. Monasterio \& Ávila. R. P. (2004) encontraram velocidades de convergência absoluta (incondicional) oscilando entre 1\% e 1,3\% para 58 áreas comparáveis do Rio Grande do Sul entre 1939 e 2001. Barreto \& Almeida (2009) estimaram um período de meiavida de 43,18 anos (equivalente a uma velocidade de convergência de 1,6\%), para os municípios do Ceará, entre 1996 e 2003. A exceção ocorreu em Perobelli et al. (2007), onde foi encontrada uma velocidade de convergência absoluta de 7,5\% a.a. para os municípios de MG, entre 1975 e 2003. Para Canova \& Marcet (1999), esses resultados indicam que, uma vez controladas as principais características das regiões, existe uma tendência de diminuição das diferenças de renda regionais.

${ }^{50}$ Como este trabalho utilizou dados cross-section (e não painel) a heterogeneidade espacial precisou ser controlada por meio da partição dos dados. Nesses casos, geralmente, utiliza-se algum tipo de agrupamento ou regime espacial a fim minimizar a heterogeneidade espacial. Na literatura nacional, alguns autores conseguiram acomodar os efeitos espaciais (autocorrelação e heterogeneidade) usando algum tipo de regime em conjunto com modelos que captam a autocorrelação espacial. Segundo Monasterio \& Ávila. R. P. (p.291 2004), a combinação de regimes espaciais com autocorrelação espacial se mostrou a especificação mais adequada para analisar o
} 
Assim, o passo seguinte consistiu em incorporar a heterogeneidade espacial verificada nos $\beta$ parâmetros. ${ }^{51}$ Para isso, usou-se uma variável categórica (discreta) para identificar regimes espaciais. A variável utilizada corresponde às 12 mesorregiões de Minas Gerais que, a princípio, poderiam apresentar dinâmicas de crescimento diferentes entre si (heterogeneidade espacial). Essa técnica permite "suavizar" a heterogeneidade espacial, atenuando os erros heterocedásticos. Segundo Anselin (1990), a estabilidade estrutural do modelo de regimes espaciais pode ser testada via teste de Chow espacial, que compara a soma dos quadrados dos resíduos da regressão com coeficientes globais para o conjunto de dados (modelo restrito - R) com a soma dos quadrados dos resíduos da regressão que utiliza coeficientes distintos para os subconjuntos dos dados (modelo irrestrito - IR). Formalmente:

$$
\text { Chow }=\left\{\left[\frac{\left(\varepsilon_{R}^{\prime} \varepsilon_{R}-\varepsilon_{I R}^{\prime} \varepsilon_{I R}\right)}{k}\right]\left[\frac{1}{(n-2 k)}\right]\right\} F_{k, n-2 k}
$$

onde se testa $H_{0}$ : Há estabilidade estrutural conjunta dos coeficientes da regressão.

Logo, é possível verificar se existem respostas distintas dependendo do subconjunto de dados. Os resultados associados ao modelo de transbordamento espacial com mudança estrutural nos parâmetros, definida pela variável categórica, são apresentado na Tabela 4.

Inicialmente, verifica-se por meio do teste de Koenker-Bassett que o modelo estimado por MQO, considerando os 853 municípios de Minas Gerais, apresenta heterocedasticidade. Logo, deve-se utilizar a versão robusta do MQO, com a inclusão da matriz de White, para analisar a significância dos testes de Estabilidade dos $\beta$ Individuais. Além disso, o teste de Chow rejeita, amplamente, a hipótese nula, $H_{0}$. Logo, há indícios de instabilidade estrutural (coeficientes variam, significativamente, entre as mesorregiões) e o modelo de regimes é recomendável. Embora o modelo tenha diminuído ainda mais a autocorrelação ( $I$ de Moran diminui de 0,20, no modelo 3.1 da Tabela 3, para 0,19 ) ele ainda não foi capaz de eliminá-la.

Como o teste Jarque-Bera indicou que os erros não são normais, utilizou-se o mesmo procedimento de mapeamento dos resíduos utilizado no modelo 3.1. No entanto, em vez de utilizar dummies, tais municípios foram excluídos da amostra. $^{52}$ Os resultados estão dispostos no modelo sem outliers da Tabela 4. Nota-se que, mais uma vez, o procedimento conseguiu eliminar o problema de não normalidade dos resíduos. Além disso, o I de Moran produzido por essa regressão foi não significativo, indicando que a autocorrelação foi controlada. Como o teste de Breusch-Pagan ainda acusa alguma heterocedastici-

crescimento econômico do Rio Grande do Sul. Já Gonçalves et al. (p.310 2011) argumentam que a heterocedasticidade foi controlada a partir da divisão da amostra em grupos. Almeida et al. (2008) também se valem desse procedimento. Embora essa técnica seja útil para dados crosssection, ela não seria necessária em dados em painel, pois, por meio de um modelo de efeitos fixos ou primeiras diferenças, seria possível eliminar todo o efeito associado à heterogeneidade espacial.

${ }^{51}$ A heterogeneidade espacial pode ser tratada pela adaptação espacial da proposta de Quandt (1958). Nesse caso, assume-se que o sistema siga dois ou mais regimes no espaço. Cada regime espacial representa a resposta ao fenômeno em estudo de um subconjunto dos dados, definidos por um critério geográfico. Assim, os coeficientes (tanto intercepto quanto inclinação) podem variar conforme o regime espacial (Almeida 2012).

${ }^{52}$ Os municípios excluídos (outliers) podem ser visualizados na Tabela A.1, no Apêndice. 
Tabela 3: Estimação dos Modelos de Crescimento para os Municípios de MG

\begin{tabular}{|c|c|c|c|c|c|}
\hline \multirow[t]{2}{*}{ Variáveis } & \multicolumn{5}{|c|}{ Variável dependente: $W_{-} \ln \left(\frac{Y_{t}}{Y_{t-1}}\right)$} \\
\hline & {$[1]$} & [2] & {$[3]$} & {$[4]$} & {$[3,1]$} \\
\hline Constante & $1,543^{* * *}$ & $1,581^{* * *}$ & $1,590^{* * *}$ & $1,727^{* * * *}$ & $1,569^{* * *}$ \\
\hline $\ln \left(Y_{t-1}\right)$ & $-0,125^{* * *}$ & $-0,142^{* * *}$ & $-0,150^{* * *}$ & $-0,151^{* * * *}$ & $-0,144^{* * *}$ \\
\hline $\ln (n+g+\delta)$ & $-0,002$ & $-0,002$ & 0,019 & 0,018 & 0,011 \\
\hline $\ln \left(K_{t}\right)^{\circ}$ & $0,252^{* * *}$ & $0,200^{* * *}$ & $0,228^{* * *}$ & $0,244^{* * *}$ & $0,217^{* * *}$ \\
\hline $\ln \left(H 1_{t}\right)$ & - & $0,075^{* * *}$ & $0,085^{* * *}$ & $0,070^{* * * *}$ & $0,082^{* * *}$ \\
\hline $\ln \left(H 2_{t}\right)$ & - & $0,043^{* * *}$ & $0,039^{* * *}$ & $0,040^{* * *}$ & $0,043^{* * *}$ \\
\hline$W_{-} \ln \left(Y_{t-1}\right)$ & - & - & $0,043^{* * *}$ & $0,052^{* * *}$ & $0,032^{* *}$ \\
\hline$W_{-} \ln (n+g+\delta)$ & - & - & $0,112^{*}$ & $0,157^{* *}$ & $0,107^{*}$ \\
\hline$W_{-} \ln \left(K_{t}\right)$ & - & - & $-0,384^{* * *}$ & $-0,448^{* * * *}$ & $-0,349^{* * *}$ \\
\hline$W_{-} \ln \left(H 1_{t}\right)$ & - & - & $-0,268^{* *}$ & $-0,319^{* *}$ & $-0,213^{*}$ \\
\hline$W_{-} \ln \left(H 2_{t}\right)$ & - & - & $0,198^{* * *}$ & $0,218^{* * * *}$ & $0,202^{* * *}$ \\
\hline$W_{-} \ln \left(\frac{Y_{t}}{Y_{t-1}}\right)$ & - & - & - & $-0,122^{* * *}$ & - \\
\hline$W_{u}$ & - & - & - & - & - \\
\hline D_max, & - & - & - & - & $0,095^{* * *}$ \\
\hline D_min, & - & - & - & - & $-0,082^{* * *}$ \\
\hline Vel, Conv, Direta & $1,48 \%$ & $1,70 \%$ & $1,81 \%$ & $1,61 \%$ & $1,73 \%$ \\
\hline Vel, Conv, Total & $1,48 \%$ & $1,70 \%$ & $1,26 \%$ & $1,03 \%$ & $1,32 \%$ \\
\hline Meia-Vida (anos) & 46,7 & 40,7 & 55,1 & 67,5 & 52,5 \\
\hline \multicolumn{6}{|c|}{ Testes de normalidade (a) e homocedasticidade dos resíduos (b, c, d) } \\
\hline a,Jarque-Bera & $67,9^{* * *}$ & $94,6^{* * *}$ & $100,3^{* * *}$ & - & 1,4 \\
\hline b,Koenker-Bassett & $27,5^{* * *}$ & $27,8^{* * *}$ & $29,3^{* * *}$ & - & - \\
\hline c,White & $74,1^{* * *}$ & $83,5^{* * *}$ & $132,2^{* * *}$ & - & - \\
\hline d, Breusch-Pagan & - & - & - & - & $24,8^{* *}$ \\
\hline \multicolumn{6}{|c|}{ Testes de autocorrelação Espacial } \\
\hline I de Moran (resíd,) & $0,413^{* * *}$ & $0,390^{* * *}$ & $0,276^{* * *}$ & $0,354^{* * *}$ & $0,205^{* * *}$ \\
\hline \multicolumn{6}{|c|}{ Testes de qualidade dos modelos } \\
\hline AIC & $-3508,7$ & $-3566,5$ & $-3607,7$ & $-3539,6$ & $-3798,4$ \\
\hline $\mathrm{SC}$ & $-3489,7$ & $-3538,0$ & $-3555,5$ & $-3482,6$ & $-3736,6$ \\
\hline$R^{2}$ Ajustado & 0,432 & 0,470 & 0,498 & 0,457 & 0,600 \\
\hline
\end{tabular}

Fonte: Elaboração dos autores com base nos resultados obtidos através do software SpaceStat.

Notas: 1. p-valor: ${ }^{*}<0,10 ;{ }^{* *}<0,05 ;{ }^{* * *}<0,01.2$. Os modelos descritos são: (1)

Solow (1956); (2) MRW (1992), com inclusão de "saúde"; (3) Modelo 2 com transbordamentos (modelo regressivo cruzado espacial); (4) Modelo 3 com Defasagem espacial (Modelo de Durbin espacial); 3. (1), (2), (3) e (3.1) foram estimados por MQO robusto. O modelo (4) foi obtido via MQ2E, usando os instrumentos recomendados por Kelejian e Prucha (1998). 4. Para acomodar a heterocedasticidade, utilizou-se uma especificação robusta baseada na matriz de variância-covariância consistente de White para (1), (2), (3), (3.1) e (4). 5. Os testes estão baseados nas versões não robustas dos modelos. 6. D_máx e D_mín são outliers (superiores e inferiores) dos erros das regressões 3 (detectados via AEDE). 
dade no modelo, devem-se analisar os resultados da versão robusta. Os testes sobre os coeficientes individuais indicam que apenas $\ln \left(H 2_{t}\right), W_{-} \ln \left(Y_{t-1}\right)$ e $W_{-} \ln \left(H 1_{t}\right)$ são estáveis (homogêneas) entre as mesorregiões. Ou seja, seus coeficientes não apresentam variação significativa no espaço. ${ }^{53}$ Para todas as demais variáveis há uma diferença significativa entre os coeficientes. ${ }^{54}$

Tabela 4: Testes de Estabilidade Estrutural do Modelo 3 com Regimes Espaciais

\begin{tabular}{|c|c|c|c|c|}
\hline & \multicolumn{2}{|c|}{ Modelo Populacional } & \multicolumn{2}{|c|}{ Modelo sem Outliers } \\
\hline & MQO & MQO Robusto & MQO & MQO Robusto \\
\hline Chow & $3,19^{* * *}$ & - & $4,47^{* * *}$ & - \\
\hline Chow_White & - & $589,18^{* * *}$ & - & $809,44^{* * *}$ \\
\hline Variáveis & \multicolumn{4}{|c|}{ Teste de Estabilidade dos $\beta$ Individuais } \\
\hline Constante & $2,59^{* * *}$ & $29,48^{* * *}$ & $2,23^{* *}$ & $21,82^{* *}$ \\
\hline $\ln \left(Y_{t-1}\right)$ & $2,65^{* * *}$ & $30,92^{* * *}$ & $2,79^{* * *}$ & $29,48^{* * *}$ \\
\hline $\ln (n+g+\delta)$ & $1,98^{* *}$ & $18,87^{*}$ & $2,37^{* * *}$ & $24,76^{* *}$ \\
\hline $\ln \left(K_{t}\right)$ & $2,83^{* * *}$ & $37,58^{* * *}$ & $4,17^{* * *}$ & $46,94^{* * *}$ \\
\hline $\ln \left(H 1_{t}\right)$ & 1,21 & 13,89 & 1,85 & $18,80^{*}$ \\
\hline $\ln \left(H 2_{t}\right)$ & 0,89 & 10,25 & 1,3 & 14,33 \\
\hline$W_{-} \ln \left(Y_{t-1}\right)$ & 1,12 & $19,48^{*}$ & 0,95 & 15,52 \\
\hline$W_{-} \ln (n+g+\delta)$ & $1,58^{*}$ & $21,65^{* *}$ & $1,62^{*}$ & $19,46^{*}$ \\
\hline$W_{-} \ln \left(K_{t}\right)$ & 0,90 & 14,72 & 1,30 & $18,36^{*}$ \\
\hline$W_{-} \ln \left(H 1_{t}\right)$ & 0,93 & 11,41 & 0,92 & 11,04 \\
\hline$W_{-} \ln \left(H 2_{t}\right)$ & 1,35 & $18,41^{*}$ & $2,54^{* * *}$ & $30,73^{* * *}$ \\
\hline Koenker-Bassett & $35,31^{* * *}$ & - & & - \\
\hline Breusch-Pagan & - & - & $23,74^{* *}$ & - \\
\hline Jarque-Bera & $105,60^{* * *}$ & $105,60^{* * *}$ & 1,50 & 1,50 \\
\hline$R^{2}$ Ajustado & 0,618 & 0,618 & 0,699 & 0,699 \\
\hline AIC & $-3731,60$ & $-3731,60$ & $-3928,84$ & $-3928,84$ \\
\hline SC & $-3104,70$ & $-3104,70$ & $-3305,46$ & $-3305,46$ \\
\hline I de Moran (resíduo) & $0,189^{* * * *}$ & $0,189^{* * *}$ & 0,013 & 0,013 \\
\hline
\end{tabular}

Fonte: Elaboração dos autores com base no Software SpaceStat.

Nota: p-valor: ${ }^{*}<0,10 ;^{* *}<0,05 ;{ }^{* * *}<0,01$.

Em especial, o fato de $\ln \left(Y_{t-1}\right)$ ter apresentado valor de teste bastante significativo (Tabela 4) indica que o coeficiente dessa variável não é homogêneo entre as regiões e, portanto, existem clubes de convergência em Minas Gerais que são determinados pelo posicionamento geográfico. ${ }^{55}$ Note que o modelo com regimes espaciais estimado leva em consideração as características estruturais de cada região (estoque de capital físico, ensino, condições de saúde etc.). Logo, era de se esperar, segundo a hipótese de convergência condicional, que o índice de convergência, captado por $\ln \left(Y_{t-1}\right)$ variasse pouco. Como os resultados indicam que cada mesorregião apresenta sua própria velocidade

\footnotetext{
${ }^{53}$ De qualquer maneira, todos os resultados locais (para mesorregiões) foram reportados na Tabela 5.

${ }^{54}$ Para maiores detalhes sobre a análise de modelos com regimes espaciais ver Anselin (1992, cap.32, p.238).

${ }^{55}$ Gondim et al. (2007) já haviam demonstrado que tanto a educação como a localização geográfica são importantes para determinar a formação de clubes de convergência. No caso do presente artigo, a educação já havia sido controlada na estimação do modelo 3.1. Logo, faltava considerar o aspecto geográfico.
} 
de convergência, pode-se inferir que a hipótese de clubes de convergência se sobrepõe à condicional. ${ }^{56}$

A Tabela 5 indica que a constante, novamente, apresentou coeficiente superior às demais variáveis explicativas. ${ }^{57}$ Além disso, apenas a constante e a riqueza inicial, $\ln \left(Y_{t-1}\right)$, foram significativas e apresentaram o sinal esperado em todas as 12 mesorregiões. Notou-se ainda uma forte correlação negativa entre os coeficientes obtidos por essas duas variáveis $(-0,81) \cdot{ }^{58}$ Logo, as regiões que obtiveram os maiores coeficientes associados ao termo constante também auferiram as maiores taxas de crescimento e, consequentemente, apresentaram taxas de convergência maiores. ${ }^{59}$ O Norte de Minas (2), por exemplo, obteve o maior coeficiente para a constante $(1,87)$ e o menor valor para $\ln \left(Y_{t-1}\right)(-0,23)$. Enquanto isso, o Sul/Sudeste de Minas (10) obteve o menor valor para a constante $(1,59)$ e o maior valor em $\ln \left(Y_{t-1}\right)(-0,15)$.

De acordo com a Tabela 5 , a variável $\ln (n+g+\delta)$, que havia sido não significativa na maioria das modelos, mostrou-se relevante apenas em 5 das 12 mesorregiões [com destaque para o Vale do Mucuri (4) e Jequitinhonha (3)]. Quanto ao capital físico - $\mathrm{Ln}(\mathrm{Kt})$, ao capital humano - $\ln \left(H 1_{t}\right)$ e às condições de saúde - $\ln \left(H 2_{t}\right)$, observa-se que todas impulsionam o crescimento e seus impactos médios mantiveram o mesmo ordenamento do modelo sem regimes: $\beta_{K}>\beta_{H 1}>\beta_{H 2}$. Porém, verificou-se uma elevada correlação negativa entre os coeficientes de $\ln \left(K_{t}\right)$ e $\ln \left(H 1_{t}\right)(-0,84)$, indicando que nas regiões onde o impacto do capital físico é baixo, o impacto do ensino tende a ser alto [ex.: Campo das Vertentes (11)].

Logo, é possível que mesorregiões com elevado estoque de capital físico $(K)$ apresentem, simultaneamente, um baixo retorno oriundo do investimento em $K$ e um elevado retorno do investimento em capital humano. No caso do capital físico, isso ocorreria devido à produtividade marginal decrescente dos fatores de produção. Já no caso do capital humano, o próprio estoque de capital físico poderia fornecer as condições necessárias para um maior retorno oriundo de investimentos em $H 1$. Nesse sentido, mesorregiões com elevado estoque de capital físico, provavelmente, disporiam de boa infraestrutura, o que poderia impulsionar o crescimento, conforme sugerido por Hall \& Jones (1999). Assim, haveria uma relação de complementaridade entre essas variáveis de modo que o investimento em capital humano surtiria maior efeito nas regiões onde o estoque de capital físico é maior.

No caso das variáveis defasadas espacialmente, obteve-se resultados significativos apenas para uma parcela reduzida das regiões analisadas. Porém, em alguns casos, os efeitos dessas variáveis foram maiores que os das não defasadas. O coeficiente positivo encontrado para a variável $W_{-} \ln \left(Y_{t-1}\right)$ tende a re-

\footnotetext{
${ }^{56}$ Coelho \& Figueiredo (2007), analisando o crescimento da renda dos municípios brasileiros entre 1970-2000, também chegaram a essa conclusão. Além disso, Santos et al. (2012) também encontraram evidência de grupos de convergência para os municípios de Minas Gerais entre 1985 a 2005. No entanto, eles utilizaram a própria renda inicial para selecionar os grupos de municípios por meio de um modelo threshold.

${ }^{57}$ Isso ocorre em quase todas as mesorregiões, apenas $W_{-} \ln \left(Y_{t-1}\right)$ e $W_{-} \ln \left(K_{t}\right)$, ambas localizadas no Noroeste de Minas (1), apresentaram coeficiente superior (e significativo) ao menor valor encontrado para a constante.

${ }^{58}$ Essa relação inversa fica mais evidente quando os coeficientes apresentados na Tabela 5 são ordenados (conforme a magnitude) e mapeados por mesorregião (ver Tabela A.2, no Apêndice).

${ }^{59}$ Lembrando que a constante não capta somente o diferencial tecnológico das regiões analisadas, mas também as dotações, clima, instituições e outras características que influenciem o crescimento Mankiw et al. (1992).
} 


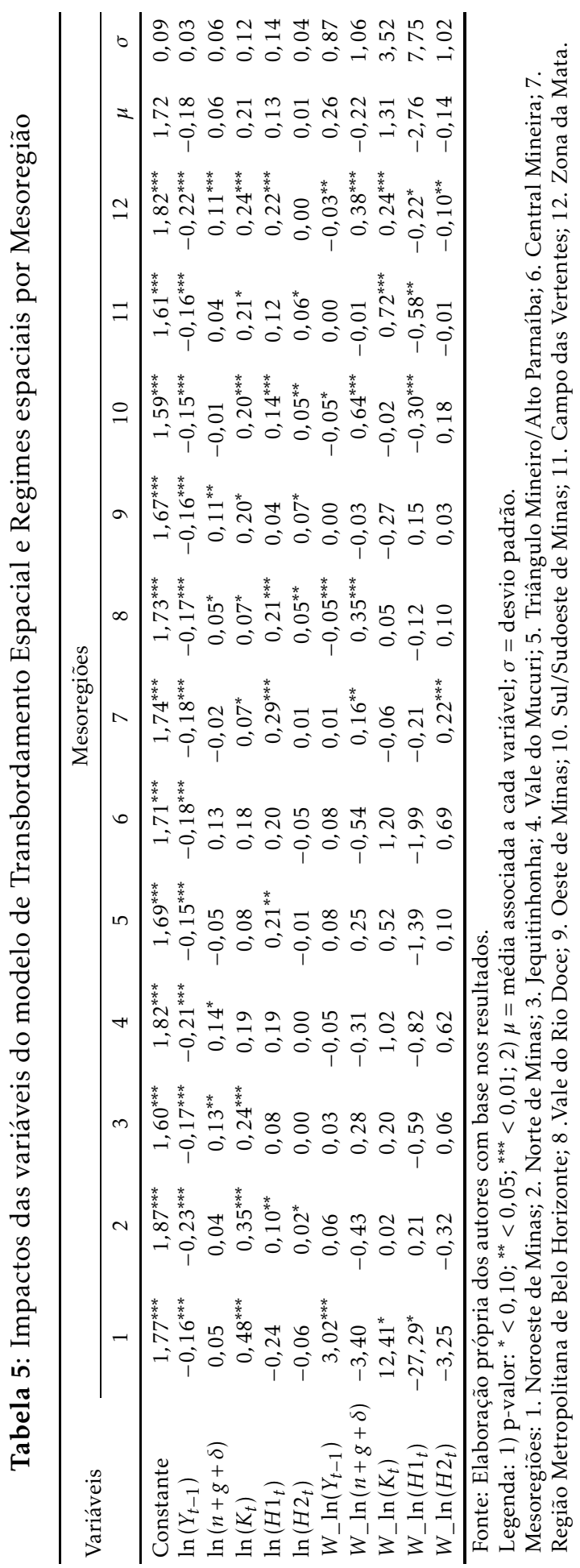


duzir o efeito da convergência. Fato este que afetaria com maior intensidade o Noroeste de Minas (1). Os valores positivos, obtidos em $W_{-} \ln (n+g+\delta), W_{-} \ln \left(K_{t}\right)$ e $W_{-} \ln \left(H 2_{t}\right)$ foram maiores que seus respectivos não defasados. Assim, pode ser que o crescimento de algumas regiões, no que se refere a esses fatores mencionados, dependa mais do que ocorre com as regiões vizinhas do que delas mesmas. ${ }^{60}$ Com relação à $W \_\ln \left(H 1_{t}\right)$, novamente o resultado foi negativo, indicando que uma melhora nas condições de ensino dos vizinhos de uma região $i$ poderia atrair o crescimento para essas regiões em detrimento de $i$. Nesse caso, o Noroeste de Minas (1) seria o mais afetado (Tabela 5).

\section{Considerações Finais}

Este artigo analisou os condicionantes do crescimento da renda per capita dos municípios de Minas Gerais, entre 1991 e 2000, utilizando o modelo de Mankiw et al. (1992) com controle para condições de saúde e robusto contra heterogeneidade e autocorrelação espacial. Segundo a literatura consultada, a exclusão de aspectos de saúde poderia enviesar o modelo, supervalorizando o impacto de outras variáveis como a educação. Além disso, desconsiderar os efeitos espaciais poderia tornar as estimações inconsistentes e/ou ineficientes.

Como a literatura tem encontrado dificuldade em definir boas proxies para o capital físico, humano e condições de saúde, diversas variáveis foram testadas no intuito de determinar quais seriam as mais adequadas para compor o modelo. Segundo os resultados, o estoque de capital residencial, os anos de estudos das pessoas de 25 anos ou mais (ponderado pelo IDH educação) e o IDH longevidade seriam as variáveis mais indicadas para representar o capital físico $(\mathrm{K})$, humano $(\mathrm{H} 1)$ e as condições de saúde $(\mathrm{H} 2)$, respectivamente.

As técnicas de AEDE aplicadas sobre a variável dependente indicaram a presença dos dois efeitos espaciais mencionados. Primeiramente, buscou-se controlar a autocorrelação espacial. Logo, algumas especificações espaciais foram testadas a fim de verificar se o efeito espacial residia na variável dependente, nas variáveis explicativas ou em uma combinação de ambas. Os resultados indicaram que a renda dos municípios de Minas Gerais converge a uma velocidade que pode oscilar entre $1,03 \%$ e $1,70 \%$ ao ano. Contudo, verificou-se que os modelos sem controles espaciais tendiam a supervalorizar esses resultados.

O modelo de transbordamento espacial foi o que melhor acomodou a autocorrelação espacial. Logo, parece que o efeito espacial estava presente apenas nas variáveis explicativas Como esse modelo apresentava erros com distribuição não normal e não foi capaz de eliminar totalmente a autocorrelação espacial, utilizou-se o método de controle de erros discrepantes (via variáveis dummy). Essa especificação se mostrou superior e atenuou ainda mais a autocorrelação espacial. Todavia, o problema persistiu em menor nível.

Dado que a heterogeneidade espacial, verificada nas técnicas de AEDE, também induz à autocorrelação, estimou-se um modelo com regimes espaciais (considerando, como regime, as 12 mesorregiões de Minas Gerais) utilizando a especificação espacial de transbordamentos nas variáveis explicativas e correção para erros discrepantes. Dessa vez, a autocorrelação foi, de fato, eli-

\footnotetext{
${ }^{60}$ Deve-se tomar cuidado ao analisar o resultado de $W_{-} \ln \left(K_{t}\right)$, uma vez que ele não é robusto, em termos de sinal obtido, quando se considera o modelo 3.1 (Tabela 3) e o modelo $3.1 \mathrm{com}$ regimes espaciais (Tabela 5).
} 
minada. Os resultados desse modelo indicaram que a constante, que em tese mediria as diferenças regionais de tecnologia, clima, instituições, dotações de recursos, entre outros, é um dos fatores mais importantes para determinar o crescimento econômico. O capital físico, $\ln \left(K_{t}\right)$, humano $\ln \left(H 1_{t}\right)$ e as condições de saúde, $\ln \left(H 2_{t}\right)$, impulsionam o crescimento e seus impactos relativos apresentam a seguinte ordenação: $\beta_{K}>\beta_{H 1}>\beta_{H 2}$. A variável $\ln (n+g+\delta)$, não foi significativa nos modelos globais (sem regimes espaciais). Já na estimação com regimes, ela se mostrou positiva e significativa para algumas mesorregiões. Embora não tenha apresentado o sinal esperado, conforme proposto por Mankiw et al. (1992), pode ser que a facilidade de migração entre municípios tenha alterado o sentido dessa variável. Assim, municípios com maiores taxas de crescimento econômico (ou melhores condições de ensino, saúde e etc.) poderiam atrair indivíduos de municípios vizinhos. Nesse caso haveria uma correlação positiva entre as taxas de crescimento econômico e populacional. Além disso, verificou-se que o índice de convergência, captado por $\ln \left(Y_{t-1}\right)$, não foi homogêneo entre as regiões de $\mathrm{MG}$, sugerindo a prevalência de clubes de convergência, determinados pelo posicionamento geográfico de cada região no Estado.

O efeito transbordamento, medido pelas variáveis defasadas espacialmente, foi verificado em um número reduzido de mesorregiões. Porém, quando é significativo, causa impactos superiores ao das variáveis não defasadas. Logo, nas regiões onde esse efeito ocorre, o efeito vizinhança pode ser mais importante para o crescimento que os fatores internos.

Por fim, a correlação entre os coeficientes, obtidos no modelo com regimes espaciais, revelou que as regiões que obtiveram os maiores coeficientes associados ao termo constante também auferiram as maiores taxas de crescimento e, consequentemente, apresentaram taxas de convergência maiores. Além disso, verificou-se que nas regiões onde o impacto do capital físico $(K)$ é baixo, o impacto do capital humano (H1) tende a ser alto. Logo, é possível que mesorregiões com elevado estoque de $K$ apresentem, simultaneamente, um baixo retorno oriundo do investimento em $K$ e um elevado retorno do investimento em H1. Assim, haveria uma relação de complementaridade entre essas variáveis, de modo que o investimento em capital humano surtiria maior efeito nas regiões onde o estoque de capital físico é maior.

\section{Agradecimentos}

Os autores gostariam de agradecer ao Professor Eduardo Simões de Almeida (UFJF), por suas considerações acerca dos estimadores espaciais, à Professora Lízia de Figueirêdo (UFMG), pelas contribuições referentes à especificação dos modelos macroeconômicos e à Professora Maria Viviana de Freitas (UFRRJ), pelo auxílio prestado à análise da convergência.

\section{Referências Bibliográficas}

Almeida, E. (2012), Econometria Espacial Aplicada, 1a ed. edn, Alínea, Campinas.

Almeida, E. S., Perobelli, F. S. \& Ferreira, P. G. C. (2008), 'Existe convergência espacial da produtividade agrícola no brasil?', Revista de Economia e Sociologia Rural 46(1), 031-052. 
Anselin, L. (1988), Spatial econometrics: methods and models, 1a ed. edn, Kluwer Academic, Dordrecht.

Anselin, L. (1990), 'Spatial dependence and spatial structural instability in applied regression analysis', Journal of Regional Science 30(2), 185-207.

Anselin, L. (1992), SpaceStat TUTORIAL: A Workbook for Using SpaceStat in the Analysis of Spatial Data, Mimeo, University of Illinois.

Anselin, L. (1995), 'Local indicators of spatial association - lisa', Geographical Analysis 27(2), 93-115.

Anselin, L. (1999), Interactive techniques and exploratory spatial data analysis, in P. A. Longley, M. F. Goodchild, D. J. Maguire \& D. W. Rhind, eds, 'Geographic Information System: Principles, Techniques, Management and Applications', John Wiley.

Anselin, L. (2002), 'Under the hood issues in the specification and interpretation of spatial regression models', Agricultural Economics 27(3), 247-267.

Anselin, L. (2005), Exploring spatial data with geoda: a workbook, Technical report, Urbana-Champaign: University of Illinois.

Anselin, L. \& Bera, A. (1998), Spatial dependence in linear regression models with an introduction to spatial econometrics, in A. Ullah \& D. E. Giles, eds, 'Handbook of applied economic statistics', Marcel Dekker.

Azzoni, C. R. (1997), 'Concentração regional e dispersão das rendas per capita estaduais: análise a partir de séries históricas estaduais de pib, 19391995', Estudos Econômicos 27(3), 341-393.

Azzoni, C. R., Menezes Filho, N., Menezes, T. \& Silveira Neto, R. (2001), Geografia y convergência en renta entre los estados brasileños, in T. Macha \& D. Sotelsek, eds, 'Convergencia ecnómica e integración', Madrid: Ediciones Pirámide.

Barreto, R. C. S. \& Almeida, E. S. (2009), A contribuição do capital humano para o crescimento econômico e convergência espacial do pib per capita no ceará, in M. C. Holanda, E. B. S. Carvalho \& M. P. Barbosa, eds, 'Economia do Ceará em Debate 2008', Fortaleza-CE: IPECE.

Barreto, R. C. S., Almeida, E. S. \& Lima, J. E. (2010), 'Convergência espacial do PIB per capita no estado do Ceará', Revista de Economia (Curitiba) 36(3), 25-40.

Barretto, E. S. d. S. \& Mitrulis, E. (2001), 'Trajetória e desafios dos ciclos escolares no país', Estudos Avançados 15(42), 1-39.

Barro, R. (1991), 'Economic growth in a cross section of countries', The Quarterly Journal of Economics 106(425), 407-443.

Barro, R. (1996), Health and economic growth, Mimeo, Cambridge (Unpublished), MA: Harvard University.

Barro, R. J. \& Sala-I-Martin, X. (1999), Economic Growth, first edition edn, Massachussets / London, England. 
Barro, R. \& Lee, J.-W. (1994), Sources of economic growth, Carnegie Conference Series on Public Policy 10:1.

Barros Neto, G. S. \& Nakabashi, L. (2011), 'Relações entre instituições, capital humano e acumulação de capital físico nos municípios brasileiros', Economia \& Tecnologia 7(2), 1-10.

Baumont, C. (2004), Spatial effects in housing price models: do house prices capitalize urban development policies in the agglomeration of dijon (1999)?, Technical report, Université de Bourgogne, Pôle d'Economie et de Gestion.

Becker, G. S. (1962), 'Investment in human capital: A theoretical analysis', Journal of Political Economy 70(5), 9-49.

Bhargava, A., Jamison, D. T., Lau, L. J. \& Murray, C. J. L. (2001), 'Modeling the effects of health on economic growth', Journal of Health Economics $20(3), 423-440$.

Bloom, D. E., Canning, D. \& Sevilla, J. (2001), The effect of health on economic growth: theory and evidence, Working Paper 8587, Cambridge: National Bureau of Economic Research.

Borjas, G. (1987), 'Self-selection and the earnings of immigrants', American Economic Review 77(4), 531-553.

Borjas, G. J. (2001), Economics of migration, Technical report, International Encyclopedia of the Social \& Behavioral Sciences.

Cangussu, R. C., Salvato, M. A. \& Nakabashi, L. (2010), 'Uma análise do capital humano sobre o nível de renda dos estados brasileiros: Mrw versus mincer', Estudos Econômicos 40(1), 153-183.

Canova, F. \& Marcet, A. (1999), The poor stay poor: non-convergence across countries and regions, Discussion Paper 1265, CEPR.

Carvalho, T. S. \& Almeida, E. (2010), 'A hipótese da curva de kuznets ambiental global: Uma perspectiva econométrico-espacial', Estudos Econômicos 40(3), 587-615.

Cliff, A. D. \& Ord, J. K. (1981), Spatial processes: models and applications, 1a ed. edn, Pion, London.

Coelho, R. L. P. \& Figueiredo, L. (2007), 'Uma análise da hipótese da convergência para os municípios brasileiros', Revista Brasileira de Economia 61(3), 331-352.

Cravo, T., Becker, B. \& Gourlay, A. (2014), 'Regional growth and smes in brazil: A spatial panel approach', Regional Studies. No prelo.

Cravo, T. \& Soukiazis, E. (2011), 'Human capital thresholds and economic growth in brazil', Revista de Desenvolvimento Econômico 13(23), 106-120.

Dias, J. \& Dias, M. H. A. (2007), 'Crescimento econômico e as políticas de distribuição de renda e investimento em educação nos estados brasileiros: teoria e análise econométrica', Estudos Econômicos 37(4). 
Durlauf, S. \& Johnson, P. (1995), 'Multiple regimes and cross-country growth behavior', Journal of Applied Econometrics 10(4), 365-384.

Ertur, C. \& Koch, W. (2007), 'Growth, Technological Interdependence and Spatial Externalities: Theory and Evidence', Journal of Applied Econometrics 22, 1033-1062.

Evans, A. D., Green, C. J. \& Murinde, V. (2002), 'Human capital and financial development in economic growth: new evidence using the translog production function', International Journal of Finance and Economics 7(2), 123-140.

Ferreira, P. C. \& Ellery Jr, R. (1996), 'Convergência entre a renda per capita dos estados brasileiros', Revista de Econometria 16(1), 83-103.

Ferreira, R. T. \& Cruz, M. A. (2010), 'Efeitos da educação, da renda do trabalho, das transferências e das condições iniciais na evolução da desigualdade de renda nos municípios brasileiros no período de 1991 a 2000', Pesquisa e Planejamento Econômico 40(1), 103-122.

Figueiredo, L. (2011), 'Incerteza sobre o impacto do capital humano na desigualdade de renda no brasil', Economia E Tecnologia 7(1), 79-86.

FIRJAN (2012), Índice de desenvolvimento municipal da federação das indústrias do estado do rio de janeiro - firjan, Technical report, Federação das Indústrias do Estado do Rio de Janeiro - FIRJAN.

URL: Disponivel em <http://www.firjan.org.br/ifdm>

Firme, V. A. C. \& Freguglia, R. S. (2013), Análise do crescimento dos municípios brasileiros utilizando dados em painel e controles espaciais sobre o modelo de mankiw, romer e weil (1992) para o período de 1980 a 2010, in 'XIX Fórum BNB / XVIII ANPEC Nordeste'.

Firme, V. A. C. \& Vasconcelos, C. R. F. (2014), 'O setor siderúrgico nacional: uma análise inter-regional de insumo produto para o período de 1999 a 2002', Pesquisa e Planejamento Econômico 44(1), 117-167.

Fochezzato, A. \& Stulp, V. J. (2008), 'Análise de convergência de renda per capita entre os municípios do rio grande do sul, 1985 a 1998', Ensaios FEE 29(1), 41-64.

Gondim, L. B., Barreto, F. A. \& Carvalho, T. S. (2007), 'Condicionantes de clubes de clubes de convergência no brasil', Estudos Econômicos 37(1), 71100.

Gonçalves, L. R. C., Gonçalces, E. \& Oliveira Jr, L. B. (2011), 'Determinantes espaciais e socioeconômicos do suicídio no brasil: uma abordagem regional', Nova Economia 21(2), 281-316.

Greene, W. (2000), Econometric analysis, 4a ed. edn, Prentice Hall, New Jersey.

Hall, R. E. \& Jones, C. I. (1999), 'Why do some countries produce so much output per worker than others', The Quarterly Journal of Economics 114(1), 83116. 
Hamermesh, D. S. \& Rees, A. (1993), The Economics of Work and Pay, 5a ed. edn, HarperCollins College, New York.

Harrison, A. (1996), 'Openness and growth: a timeseries, cross-country analysis for developing countries', Journal of Development Economics 48(2), 419-447.

Hirvonen, L. (2010), Accounting for intergenerational earnings persistence: can we distinguish between education, skills, and health?, Working Paper 2, Swedish Institute for Social Research (SOFI).

IPEA (2012), Base de dados do instituto de pesquisa econômica aplicada, Technical report, Instituto de Pesquisa Econômica Aplicada.

URL: Disponivel em <www.ipeadata.gov.br>

Islam, N. (1995), 'Growth empirics: a panel data approach', The Quarterly Journal of Economics 110(4), 1127-1170.

Jarret, J. P. \& Selody, J. G. (1982), 'The productivity- inflation nexus in canada, 1963-1979', The Review of Economics and Statistics 64(3), 361-367.

Kelejian, H. H. \& Prucha, I. R. (1998), A generalized spatial two stage least squares procedure for estimating a spatial autoregressive model with autoregressive disturbances, Mimeo, Department of Economics, University of Maryland.

Keppe, K. C. \& Nakabashi, L. (2009), 'O capital humano nos municípios paranaenses: uma análise com regressões quantílicas', Economia E Tecnologia 5(4), 101-108.

Khasnobis, G. B. \& Bari, F. (2000), Sources of growth in south asian economics, Technical report, Global Research Project.

Knowles, S. \& Owen, P. D. (1995), 'Health capital and cross-country variation in income per capita in the mankiw romer weil-model', Economics-Letters 48(1), 99-106.

Kroth, D. \& Dias, J. (2012), 'Os efeitos dos investimentos público e privado em capitais físico e humano sobre o produto per capita dos municípios da região sul: Uma análise em painéis de dados dinâmicos', Nova Economia 22(3), 621-650.

Krueger, A. O. (1968), 'Factor endowments and per capita income differences among countries', The Economic Journal 78(311), 641-659.

Le Gallo, J. \& Ertur, C. (2003), 'Exploratory spatial data analysis of the distribution of regional per capita', Papers in Regional Science 82(2), 175-201.

Lesage, J. P. \& Pace, R. K. (2009), Introduction to Spatial Econometrics, 1a ed. edn, Chapman and Hall/CRC Press, Boca Raton.

Lucas Jr, R. E. (1988), 'On the mechanics of economic development', Journal of Monetary Economics 22(1), 3-42.

Magalhães, A. M., Hewings, G. J. D. \& Azzoni, C. R. (2005), 'Spatial dependence and regional convergence in brazil', Investigaciones Regionales 6(1), 520. 
Mankiw, N. G., Romer, D. \& Weil, D. (1992), 'A contribution to the empirics of economic growth', The Quarterly Journal of Economics 107(2), 407-437.

Maranduba Jr, N. G. \& Almeida, E. S. (2009), 'Análise de convergência espacial dos repasses da lei robin hood', Economia e Sociedade 18(3), 583-601.

Massey, D. S. (1990), 'Social structure, household strategies, and the cumulative causation of migration', Population Index 56(1), 3-26.

Mayer, D., Mora, H., Cermeño, R., Barona, A. B. \& Duryeau, S. (2000), Health, growth and income distribution in latin america and the caribbean: a study of determinants and regional and local behavior, Technical Papers 18, Washington, DC. Pan-American Health Organization. Research in Public Health.

Menezes, T. A. \& Azzoni, C. R. (2006), 'Convergência de salários entre as regiões metropolitanas brasileiras: Custo de vida e aspectos de demanda e oferta de trabalho', Pesquisa e Planejamento Econômico 36(3), 449-470.

Miller, S. M. \& Mukti, P. U. (2000), 'The effects of openness, trade orientation, and human capital on total factor productivity', Journal of Development Economics 63(2), 399-423.

Mincer, J. (1974), Schooling, experience, and earnings.

Monasterio, L. M. \& Ávila. R. P. (2004), 'Uma análise espacial do crescimento econômico do rio grande do sul (1939-2001)', Economia (Brasília) 5(2), 269296.

Montenegro, R. L. G., Lopes, T. H. C. R., Ribeiro, L. C. S., Cruz, I. S. \& Almeida, C. P. C. (2014), 'Efeitos do crescimento econômico nos estados brasileiros: uma análise de dados em painel espacial', Economia Aplicada 18(2), 215-241.

Nakabashi, L. \& Figueiredo, L. (2008), 'Capital humano: uma nova proxy para incluir aspectos qualitativos', Revista de Economia (Curitiba) 34(1), 724.

Nakabashi, L. \& Salvato, M. A. (2007), 'Human capital quality in the brazilian states', Economia (Brasília) 8(2), 211-229.

Noronha, K., Figueiredo, L. \& Andrade, M. V. (2010), 'Health and economic growth among the states of brazil from 1991 to 2000', Revista Brasileira de Estudos de População 27(2), 269-283.

Oliveira, C. A., Jacinto, P. A. \& Grolli, P. A. (2008), 'Crescimento econômico e convergência com a utilização de regressões quantílicas: um estudo para os municípios do rio grande do sul - 1970-01', Ensaios FEE 28(Ed. Especial), 671-700.

Oliveira, R. C., Almeida, E., Freguclia, R. S. \& Barreto, R. C. S. (2011), 'Desmatamento e crescimento econômico no brasil: uma análise da curva de kuznets ambiental para a amazônia legal', Revista de Economia e Sociologia Rural 49(3), 709-740. 
Pereira, A. E. G., Nakabashi, L. \& Sachida, A. (2011), Qualidade das instituições e pib per capita nos municípios brasileiros, Td. 1623, Instituto de Pesquisa Econômica Aplicada - IPEA.

Perobelli, F. S., Faria, W. R. \& Ferreira, P. G. C. (2007), 'Análise da convergência espacial do pib per capita no estado de minas gerais', Revista Brasileira de Estudos Regionais e Urbanos 1, 85-113.

Pôrto Jr, S. S. \& Ribeiro, E. P. (2000), 'Dinâmica de crescimento regional - uma análise empírica da região sul', Revista Econômica do Nordeste 31(9), 454-482.

Pôrto Jr, S. S. \& Ribeiro, E. P. (2003), 'Dinâmica espacial da renda per capita e crescimento entre os municípios da região nordeste do brasil — uma análise markoviana', Revista Econômica do Nordeste 34(3), 405-420.

Quandt, R. (1958), 'The estimation of the parameters of a linear regression system obeying two separates regimes', Journal of the American Statistical Association $\mathbf{5 3}(284), 873-880$.

Resende, G., Carvalho, T. S. \& Sakowski, P. (2014), Evaluating multiple spatial dimensions of economic growth in brazil using spatial panel data models (1970-2000), Discussion Paper 1830a, IPEA.

Rey, J. S. \& Montori, B. D. (1999), 'Us regional income convergence: a spatial econometric perspective', Regional Studies 33(2), 143-156.

Rivera-Batiz, L. (1993), Convergence of regional income in china, Working paper, UFP.

Romer, D. (1996), Advanced Macroeconomics, 1a ed. edn, McGraw - Hill: Advanced Series in Economics.

Sachs, J. D. (2001), Macroeconomics and health: investing in health for economic development, Technical report, Report of the Commission on Macroeconomics and Health - World Health Organization.

Sala-I-Martin, X. (1995), 'Regional cohesion: Evidence and theories of regional growth and convergence', European Economic Review 40(6), 1325-1352.

Salgueiro, A. S., Nakabashi, L. \& Prince, D. (2011), O papel do capital humano, spillovers e difusão tecnológica no crescimento. uma análise espacial para brasil, in '390 Encontro Nacional de Economia - ANPEC'.

Santolin, R. \& Figueiredo, L. (2010), Desigualdade interpessoal de renda: Implicações sobre o crescimento econômico dos municípios brasileiros, in ' 380 Encontro Nacional de Economia - ANPEC'.

Santos, A. M. A., Jacinto, P. A. \& Tejada, C. A. O. (2012), 'Causalidade entre renda e saúde: Uma análise através da abordagem de dados em painel com os estados do brasil', Estudos Econômicos 42(2), 229-261.

SEBRAE/MG (2012), Anuário de dados municipais do estado de minas gerais, Technical report, SEBRAE/MG.

URL: Diponivel em: <http://www.sebraemg.com.br/BibliotecaDigital> 
Shioji, E. (1993), Regional growth in japan, Mimeo, Yale University.

Silva, A. L. F., Oliveira Júnior, J. N., Diniz, M. B. \& Ferreira, R. T. (2008), Análise de clubes de convergência na amazônia legal: um abordagem sob o modelo threshold, Technical report, ANPEC Nordeste/Fórum BNB.

Silva, A. M. \& Resende, G. M. (2009), 'Crescimento econômico comparado dos municípios alagoanos e mineiros: Uma análise espacial', Economia Política do Desenvolvimento 1(6), 133-160.

Silveira Neto, R. M. \& Azzoni, C. R. (2006), 'Location and regional income disparity dynamics: The brazilian case', Papers in Regional Science 85(4), 599613.

Sjaastad, L. (1962), 'The costs and returns of human migration', Journal of Political Economy 70(5), 80-93.

Smith, A. (2009), A Riqueza das Nações: Uma Investigação sobre a Natureza e as Causas da Riqueza das Nações, 1a edição edn.

Solow, R. M. (1956), 'A contribution to the theory of economic growth', The Quarterly Journal of Economics 70(1), 65-94.

Summers, R. \& Heston, A. (1988), 'A new set of international comparisons of real product and price levels: estimates for 130 countries', The Review of Income and Wealth 4(1), 1-25.

Tavares, J. M., Ataliba, F. \& Castelar, I. (2001), 'Mensuração da produtividade total dos fatores para os estados brasileiros, sua contribuição ao crescimento do produto e influência da educação: 1986-1998', Revista Econômica do Nordeste 32(Ed. Especial), 633-653.

Tobler, W. R. (1970), 'A computer model simulation of urban growth in the detroit region', Economic Geography 46(2), 234-240.

Trompieri Neto, N., Castelar, I. \& Linhares, F. C. (2008), Convergência de renda dos estados brasileiros: uma abordagem de painel dinâmico com efeito threshold, in '360 Encontro Nacional de Economia - ANPEC'.

Vallejos, L. \& Valdivia, L. (2000), Productivity growth in peru: 1950-1998, Serie de Documentos de Trabajo 355, Santiago: Interamerican Development Bank.

Woessmann, L. (2003), 'Specifying human capital', Journal of Economic Surveys 17(3), 239-270.

Wooldridge, J. M. (2010), Introdução à Econometria: Uma Abordagem Moderna, 4a ed. norte americana edn, Cengage Learning, São Paulo.

\section{Apêndice A}



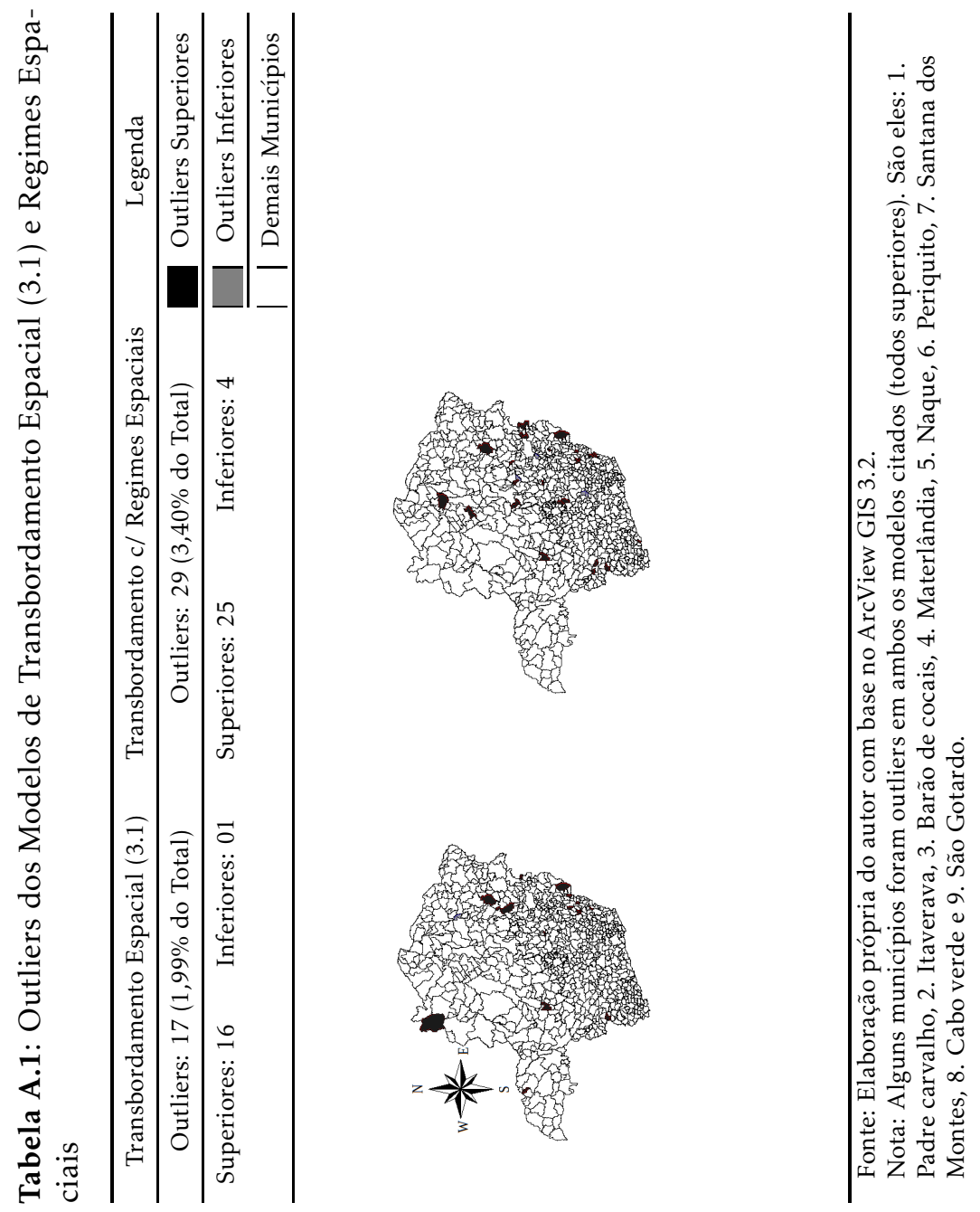


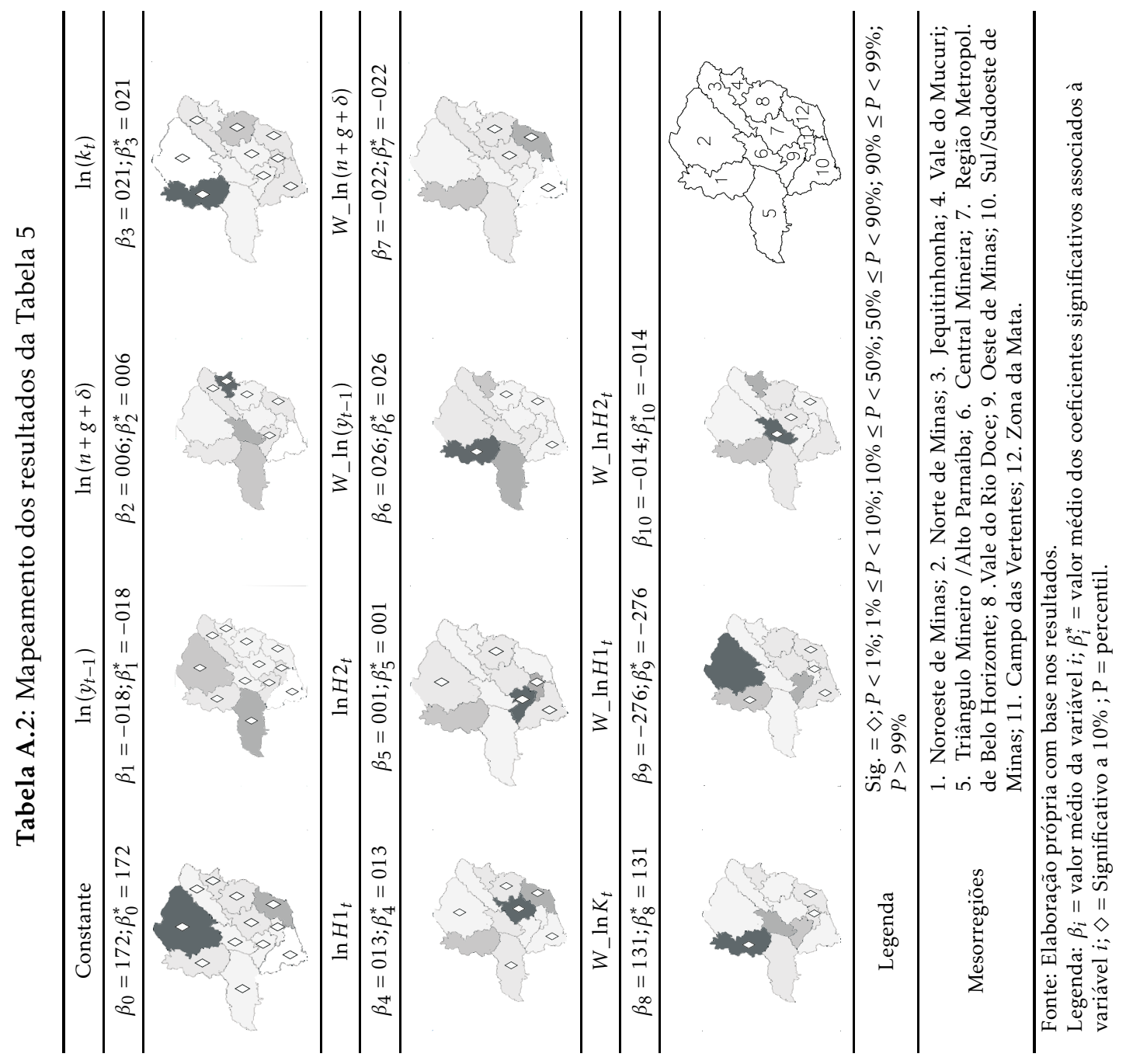


